\title{
AMP-activated protein kinase-dependent nuclear localization of glyceraldehyde 3-phosphate dehydrogenase in senescent human diploid fibroblasts
}

\author{
Jee Young Sohn ${ }^{1,}{ }^{*}$, Hyeok-Jin Kwak ${ }^{2,}{ }^{*}$, Ji Heon Rhim³, Eui-Ju Yeo ${ }^{2,4}$ \\ ${ }^{1}$ Department of Medicine, College of Medicine, Gachon University, Incheon 21999, Republic of Korea \\ ${ }^{2}$ Department of Health Sciences and Technology, GAIHST, Gachon University, Incheon 21999, Republic of Korea \\ ${ }^{3}$ Bio-New Material Development, NineBioPharm Co., Ltd., Cheongju 28161, Republic of Korea \\ ${ }^{4}$ Department of Biochemistry, College of Medicine, Gachon University, Incheon 21999, Republic of Korea \\ "Equal contribution
}

Correspondence to: Eui-Ju Yeo; email: euiju@gachon.ac.kr

Keywords: glyceraldehyde-3-phosphate dehydrogenase, AMP-activated protein kinase, nuclear localization, senescence, human diploid fibroblasts

Received: June 15, 2021

Accepted: January 3, 2022

Published: January 12, 2022

Copyright: (C) 2022 Sohn et al. This is an open access article distributed under the terms of the Creative Commons Attribution License (CC BY 3.0), which permits unrestricted use, distribution, and reproduction in any medium, provided the original author and source are credited.

\section{ABSTRACT}

Glyceraldehyde-3-phosphate dehydrogenase (GAPDH) is a key glycolytic enzyme that participates in various cellular events, such as DNA repair and apoptosis. The functional diversity of GAPDH depends on its intracellular localization. Because AMP-activated protein kinase (AMPK) regulates the nuclear translocation of GAPDH in young cells and AMPK activity significantly increases during aging, we investigated whether altered AMPK activity is involved in the nuclear localization of GAPDH in senescent cells. Age-dependent nuclear translocation of GAPDH was confirmed by confocal laser scanning microscopy in human diploid fibroblasts (HDFs) and by immunohistochemical analysis in aged rat skin cells. Senescence-induced nuclear localization was reversed by lysophosphatidic acid but not by platelet-derived growth factor. The extracellular matrix from young cells also induced the nuclear export of GAPDH in senescent HDFs. An activator of AMPK, 5-Aminoimidazole-4-carboxamide-1- $\beta$-D-ribofuranoside (AICAR), increased the level of nuclear GAPDH, whereas an inhibitor of AMPK, Compound C, decreased the level of nuclear GAPDH in senescent HDFs. Transfection with AMPK $\alpha$ siRNA prevented nuclear translocation of GAPDH in senescent HDFs. The stimulatory effect of AICAR and serum depletion on GAPDH nuclear translocation was reduced in AMPK $\alpha_{1} / \alpha_{2}$-knockout mouse embryonic fibroblasts. Overall, increased AMPK activity may play a role in the senescence-associated nuclear translocation of GAPDH.

\section{INTRODUCTION}

Cellular senescence is a complex and heterogeneous process characterized by cell cycle arrest after a limited number of cell divisions. Telomeres shorten with each mitotic division in cells, and a DNA damage response terminally arrests the cell cycle as a protective mechanism [1]. The gradual accumulation of senescent cells during aging can be associated with a progressive decline in physiological functions, promoting tissue damage and making proinflammatory environments favorable for various age-associated diseases, such as cancer, diabetes, cardiovascular diseases, and neurodegenerative diseases [2-4]. Because the incidence of age-related diseases is expected to rise as the global population of elderly individuals over 60 years is increasing rapidly [5], promising therapies and strategies for the prevention 
and treatment of age-related disorders are urgently needed [6].

Among the events associated with cellular senescence, changes in the expression and secretion of extracellular matrix (ECM) components, such as collagens, glycoproteins, proteoglycans, and ECM-associated proteins, and ECM remodeling enzymes such as matrix metalloproteinases are included [7]. Although cellular senescence is generally thought to be an absolute and irreversible process, the possibility of reversing agerelated decline in regenerative properties by exposure to a young systemic environment has been suggested [8]. In addition, young ECM has been shown to induce young phenotypes in senescent human diploid fibroblasts (HDFs) [9]. Similarly, young and adult ECM improve cardiac function, whereas aged ECM accelerates the aging phenotype in cardiomyocytes [10], supporting the utilization of ECM-based cardiac regenerative medicines [11].

Glyceraldehyde-3-phosphate dehydrogenase (GAPDH) is a key glycolytic enzyme that catalyzes the conversion of glyceraldehyde-3-phosphate into 1,3biphosphoglycerate, producing ATP and pyruvate through anaerobic glycolysis in the cytoplasm. GAPDH also participates in various cellular events, such as DNA replication and repair, transcriptional and post-transcriptional regulation of gene expression, membrane fusion and transport, autophagy, apoptosis and cellular senescence [12-16]. The functional diversity of GAPDH depends on its intracellular localization to the nucleus and other subcellular organelles such as polysomes, the ER, and the Golgi [17]. Previous studies have shown that GAPDH is translocated to the nucleus upon glucose starvation, serum depletion, oxidative stress, and genotoxic stress, through post-translational modifications of GAPDH, such as phosphorylation, oxidation, acetylation, glycosylation, S-nitrosylation, S-glutathionylation, and poly ADP-ribosylation [12, 13, 15, 18-23], and its binding with other molecules, such as Siah1 and SIRT1 [15, 24-27]. Several independent studies have shown the role of nuclear GAPDH in the pathogenesis of several age-related diseases. For instance, under oxidative conditions, GAPDH is oxidized and translocated to the nucleus to form aggregates, which act as a seed to accelerate amyloidogenesis, resulting in neurodegenerative diseases, including Alzheimer's and Parkinson's diseases [22, 28].

AMP-activated protein kinase (AMPK) is a serine/threonine protein kinase consisting of a catalytic subunit $\alpha$ and regulatory subunits $\beta$ and $\gamma$. AMPK mainly functions as an energy sensor that regulates cellular and organismal metabolism in eukaryotes
[29-33]. When energy (ATP) production decreases and the ratio of AMP to ATP increases in cells, AMPK is activated by binding of AMP or ADP to its $\gamma$ subunit and induces the phosphorylation of the $\alpha$ subunit at $\mathrm{Thr}^{172}$ via upstream AMPK kinases, such as liver kinase $\mathrm{B} 1$ (LKB1) and $\mathrm{Ca}^{2+}$-calmodulin-dependent protein kinase kinase (CaMKK) $\beta$. In contrast, AMPK activity is inhibited by dephosphorylation at $\mathrm{Thr}^{172}$ by protein phosphatases $2 \mathrm{~A} / 2 \mathrm{C}$ and phosphorylation at $\operatorname{Ser}^{485 / 491}$ of the $\alpha_{1} / \alpha_{2}$ subunits by other kinases, such as Akt, protein kinase A, and ERK [34]. AMPK coordinates energy metabolism with other cellular processes, such as cell growth, mitochondrial homeostasis, endoplasmic reticulum stress, autophagy, and apoptosis by orchestrating various signaling cascades, including mTOR and SIRT1 [34-37]. AMPK activation can occur in response to other stressful and pathological conditions, such as hypoxia, hyperosmosis, muscle contraction, production of reactive oxygen species (ROS), and exposure to genotoxic drugs [33, 38, 39].

Additionally, basal levels of protein or AMPK activity increase in senescent cells and aged tissues [4, 40, 41]. AMPK may play protective roles in aging and age-associated diseases, presumably by reducing ROS, fibrosis, and immunosuppression of critical cells or organs [42-45]. Aging is also associated with a decline in AMPK activation in response to various insults $[41,46]$. In either case, AMPK has been considered a potential therapeutic target for metabolic diseases, including type 2 diabetes, as well as other age-associated diseases [33, 47-49]. Because previous studies have revealed that AMPK is an important regulator of the GAPDH nuclear translocation in young HDFs [50], we hypothesized that the increased AMPK activity with senescence may change the intracellular localization of GAPDH, which might play a critical role in age-related functional decline and diseases. Therefore, we investigated the possibility of reversing the senescent changes in GAPDH by modifying the AMPK activity and ECM.

\section{RESULTS}

\section{Nuclear localization of GAPDH in senescent HDFs and skin cells of aged rats}

We investigated the intracellular distribution of GAPDH in young and senescent HDFs with population doubling (PD) of 16 and 72, respectively, by confocal laser scanning microscopy of immunostained HDFs. Confocal images of young and senescent cells (Y-HDFs and S-HDFs, respectively) cultured in $10 \%$ fetal bovine serum (FBS) medium or in serum-free medium for 
5 days (SFM-5d) are shown in Figure 1A. In young cells, similar to a previous study [50], GAPDH was mainly located in the cytosol with $10 \%$ FBS, and the serum withdrawal (SFM) resulted in GAPDH relocation into the nucleus. However, in senescent cells, levels of nuclear GAPDH far exceeded those of cytosolic GAPDH even in 10\% FBS medium, and cytosolic GAPDH was further relocated into the nucleus by serum depletion. GAPDH migration to the nucleus upon serum depletion was confirmed by staining the nucleus with DAPI. Confocal images for GAPDH are shown alongside DAPI-stained and merged images in Figure 1A.

The number of cells with nuclear GAPDH with or without cytosolic GAPDH (nuclear $+/-$ cytosol) was counted in the confocal images. The percentage distributions were compared in young and senescent cells cultured in $10 \%$ FBS medium for 2 days followed by serum depletion for 5 consecutive days (Figure 1B). Statistically significant differences between groups were determined by one-way ANOVA $(F(5,54)=$ $1032.474, p<10^{-3}$ ) followed by Dunnett's T3 post hoc test. In young cells, compared to $8.05 \%$ in $10 \%$ FBS medium, serum depletion resulted in a gradual increase $\left.{ }^{* * *} p<0.001\right)$ in the portion of nuclear GAPDH from day 1 until day 5 (17.95\% on day $1,38.74 \%$ on day 2 , $84.19 \%$ on day $3,92.63 \%$ on day 4 , and $94.44 \%$ on day 5). Moreover, a significant ( ${ }^{\#} p<0.01$ ) shift of cytosolic GAPDH into the nucleus was observed from days 3 to 5 of serum depletion in senescent cells with both cytosolic and nuclear GAPDH. The percentage of nuclear GAPDH dominant senescent cells was $84.56 \%$ on day $1,85.52 \%$ on day $2,89.85 \%$ on day $3,90.40 \%$ on day 4 , and $92.61 \%$ on day 5 in SFM medium, compared to $78.58 \%$ in $10 \%$ FBS medium.

Although cellular senescence contributes to aging and age-related diseases, the mechanisms are poorly understood [51]. To confirm that GAPDH is localized in the nucleus of aged or senescent cells of living organisms, young and aged rat skin was prepared, and GAPDH distribution was examined by immunohistochemistry. The distribution of GAPDH in the back skin cells of 6-month-old (young) and 24month-old (aged) rats showed similar results to the in vitro results (Figure 1C). When immunostained with monoclonal anti-GAPDH antibody, the majority of skin cells, both keratinocytes and fibroblasts, showed predominant cytosolic GAPDH distribution in young rats, whereas the majority of these skin cells showed predominant nuclear distribution in aged rats. The number of keratinocytes and fibroblasts with nuclear GAPDH was counted in young and aged skin. The percentage of cells with nuclear GAPDH was calculated and plotted in Figure 1D. Statistically significant differences between young and aged skin were determined by one-way ANOVA $(F(3,28)=486.941$, $p<10^{-3}$ ) followed by Dunnett's T3 post hoc test. Our data showed that the nuclear localization of GAPDH in the skin cells of aged organisms, keratinocytes and fibroblasts increased significantly $\left({ }^{* * *} p<0.001\right)$ compared to that in young skin cells.

\section{Growth factor-dependent relocation of nuclear GAPDH to the cytoplasm}

Previously, we have suggested that senescent cells respond to a naturally occurring phospholipid growth factor, lysophosphatidic acid (LPA), which works through G-protein coupled receptors, but not plateletderived growth factor (PDGF), which works through a receptor tyrosine kinase [52]. To assess the change in GAPDH location upon growth factor re-addition to the media, the effects of LPA and PDGF were compared. Senescent HDFs were deprived of serum by culturing with SFM for 5 days and then grown further in 100 $\mathrm{ng} / \mathrm{mL}$ PDGF or $30 \mu \mathrm{M}$ LPA for 1-48 h (Figure 2). GAPDH in senescent HDFs was located mainly in the nucleus after serum deprivation for 5 days. A portion of nuclear GAPDH was exported to the cytoplasm upon LPA addition but not upon PDGF addition to the senescent HDFs (Figure 2A). The statistically significant difference between serum-depleted cells and PDGF- or LPA-treated cells for $1-48 \mathrm{~h}$ was determined by one-way ANOVA $\left(F(4,35)=17.543, p<10^{-3}\right)$ followed by Dunnett's T3 post hoc test. The addition of PDGF yielded nuclear GAPDH dominant HDFs of $90.69 \%$ at $1 \mathrm{~h}, 90.05 \%$ at $8 \mathrm{~h}, 89.78 \%$ at $24 \mathrm{~h}$, and $90.18 \%$ at $48 \mathrm{~h}$ with $p$-values greater than 0.05 , which was not significant for all results when compared to the control SFM-treated for 5 days $(90.60 \%)$ (Figure 2B). In contrast, LPA addition yielded nuclear GAPDH dominant $\mathrm{HDF}$ of $87.47 \%$ at $1 \mathrm{~h}, 84.21 \%$ at $8 \mathrm{~h}$, $83.35 \%$ at $24 \mathrm{~h}$ and $71.37 \%$ at $48 \mathrm{~h}\left({ }^{\# \#} p<0.001\right)$ when compared to the control SFM-treated for 5 days $(88.32 \%)$ (Figure 2C). These data suggest that LPA, but not PDGF, can induce the export of nuclear GAPDH in senescent HDFs.

\section{Effect of ECM on nuclear localization of GAPDH}

To determine the effect of young and senescent ECM (Y-ECM and S-ECM, respectively) on the nuclear localization of GAPDH, subconfluent young (Y-HDFs, PD 16) and senescent HDFs (S-HDFs, PD 75) were seeded onto Y-ECM- or S-ECM-coated cover slides in 6-well plates and incubated in SFM for 5 days before immunofluorescence staining. Although the young HDFs did not show significant morphological changes in different ECMs, S-HDFs in Y-ECM showed morphological differences from the regular S-HDFs in 

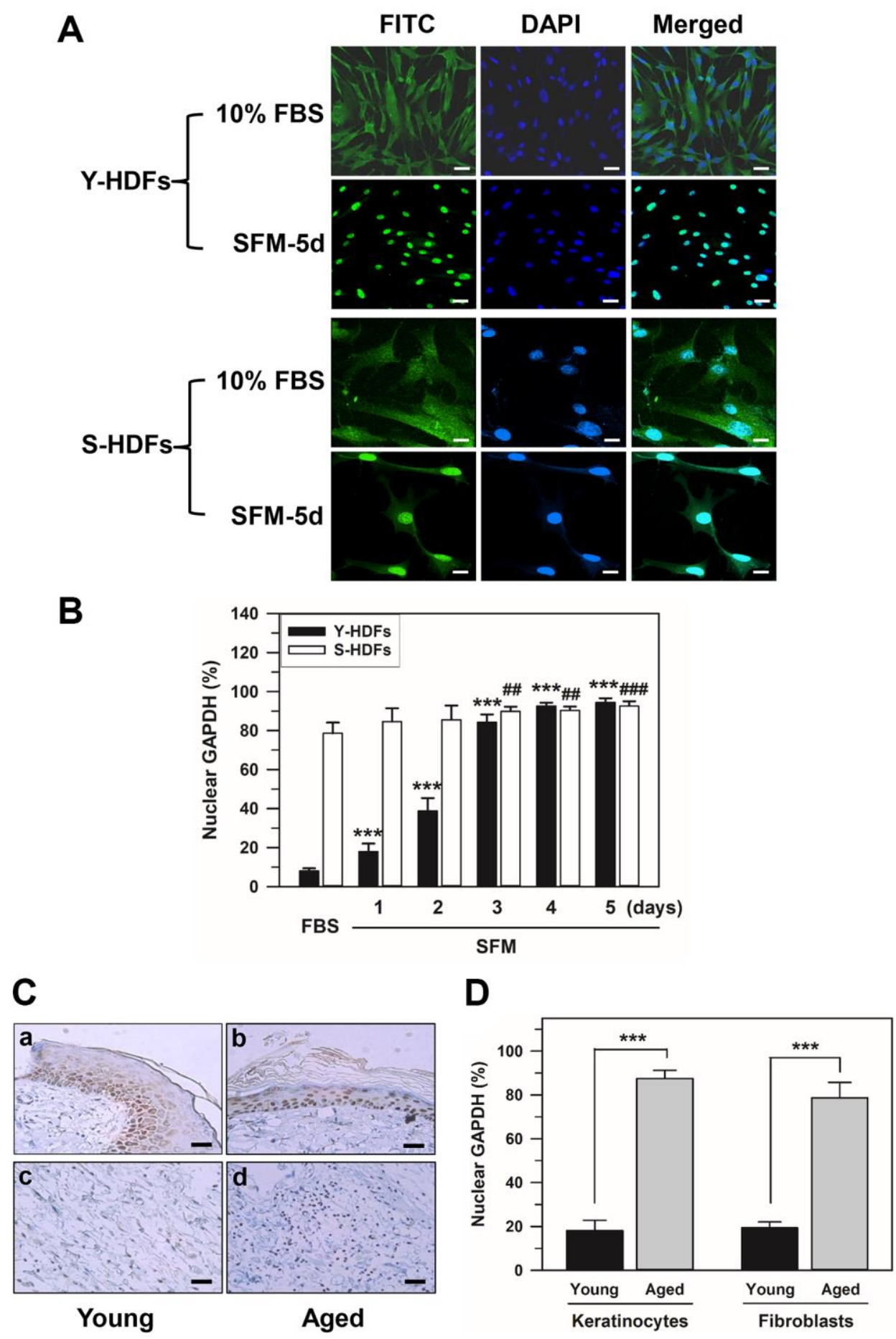

Figure 1. Nuclear accumulation of GAPDH in senescent HDFs. (A and B) Young (Y-HDFs, PD 16) and senescent (S-HDFs, PD 72) cells were maintained in DMEM containing 10\% FBS for 2 days and then serum-depleted by incubation with SFM for the indicated times (1-5 days). Cells were immunostained with monoclonal anti-GAPDH antibody and FITC-conjugated anti-mouse secondary antibodies, and analyzed by confocal laser scanning microscopy (magnification, 100x; scale bar, $50 \mu \mathrm{m}$ ). Immunostained young and senescent cells with serum (10\% FBS) and without serum for 5 days (SFM-5d) are shown in A. The number of young and senescent HDFs having nuclear GAPDH with or without cytosolic GAPDH was counted, and the percentage distribution was calculated ( $n=10$ for total replicates) and plotted as means \pm standard deviations in B. ${ }^{* * *} p<0.001$ (Y-HDFs), ${ }^{\# \#} p<0.01$ and ${ }^{\# \#} p<0.001$ (S-HDFs), compared with 10\% FBS-treated control cells. (C) The levels of GAPDH in the back skin cells from young ( 6 months, a and c) and aged ( 24 months, $b$ and d) rats were detected by immunohistochemistry and the epithelial layers containing mainly keratinocytes ( $a$ and $b$ ) and fibroblasts ( $c$ and d) were photographed by light microscopy and the $\times 200$ magnified photos with $50 \mu \mathrm{m}$ scale bar are shown. Each experiment was performed at least three times with similar results. (D) The number of keratinocytes and fibroblasts with nuclear GAPDH was counted in young and aged skin (C), the percentage of cells with nuclear GAPDH was calculated ( $n=8$ for total replicates) and plotted as means \pm standard deviations. ${ }^{* * *} p<0.001$, compared between young and aged skin. 
S-ECM (Figure 3A). A portion of S-HDFs in Y-ECM showed young-like phenotype. The number of HDFs with cytosolic GAPDH alone and HDFs with nuclear GAPDH with or without cytosolic GAPDH were counted, and the percentage distributions are plotted in Figure 3B. Statistically significant differences between groups were determined by one-way ANOVA $(F(3,68)$ $=499.517, p<10^{-3}$ ) followed by Dunnett's T3 post hoc test. As shown in Figure 3B, S-ECM reduced the cytosolic GAPDH levels in Y-HDFs from 94.03 to $85.06 \%\left({ }^{* * *} p<0.001\right)$, and Y-ECM increased those in S-HDFs from 14.68 to $57.98 \%\left({ }^{* * *} p<0.001\right)$. Similarly,
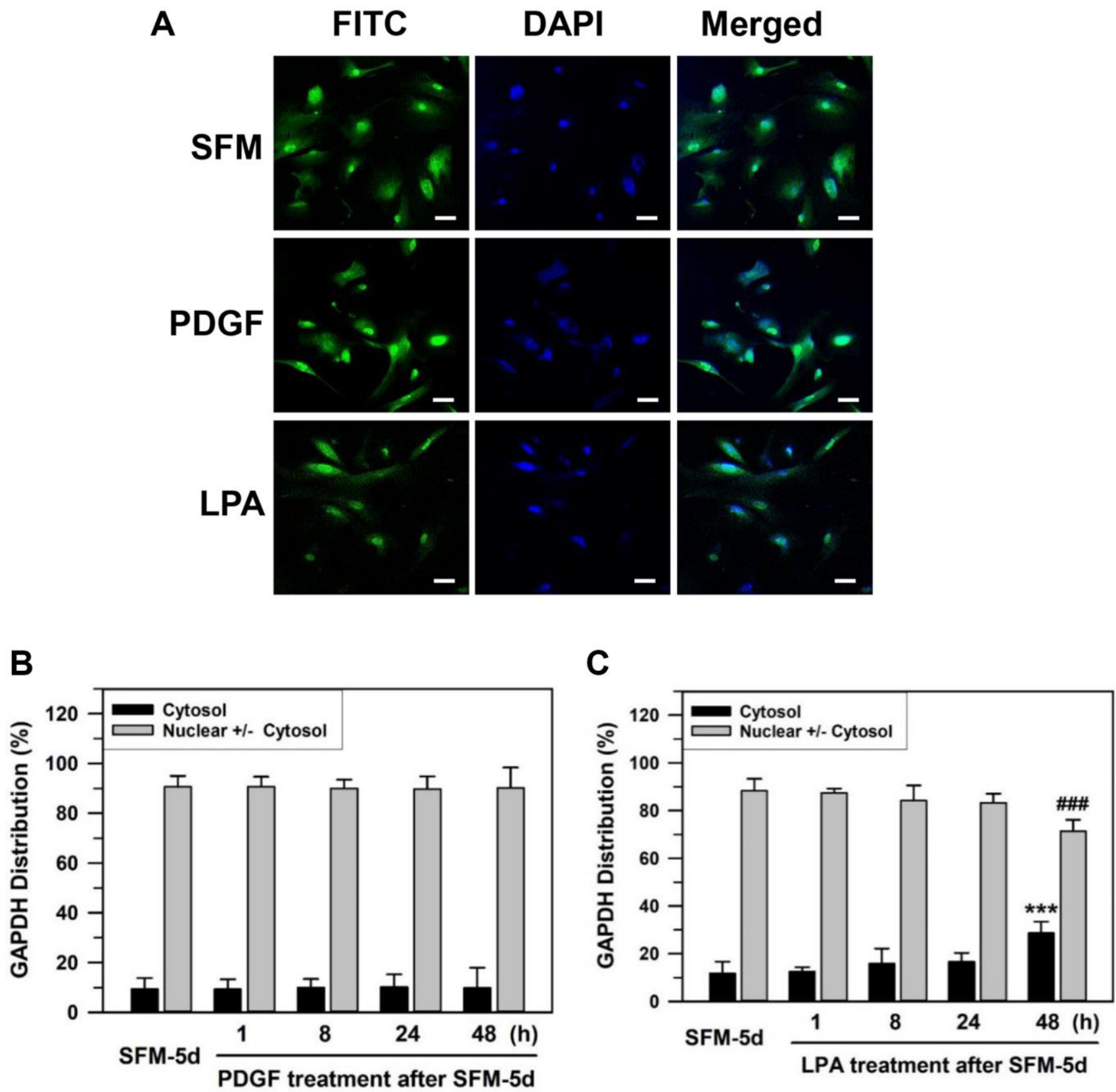

Figure 2. Effect of growth factor re-addition on the nuclear localization of GAPDH after serum depletion of senescent HDFs. (A) Subconfluent senescent HDFs were serum-depleted by incubation in SFM for 5 days. PDGF (100 ng/ml) or LPA (30 $\mu$ M) was then added to the serum-depleted cells for 2 days. Cells were immunostained against GAPDH and analyzed by confocal laser scanning microscopy. Immunostained cells with re-addition of PDGF or LPA are shown in A ( $\times 100$ with $50 \mu \mathrm{m}$ scale bar). (B and C) After the re-addition of PDGF (B) or LPA (C) for the indicated times (1-48 h), the number of cells with cytosolic GAPDH alone (Cytosol) and cells having nuclear GAPDH with or without cytosolic GAPDH (Nuclear $+/-$ Cytosol) was counted, and the percentage distributions were calculated ( $n=8$ for total replicates) and plotted as means \pm standard deviations. ${ }^{* * *} p<0.001$ (Cytosol) and ${ }^{*} p<0.001$ (Nuclear $+/-$ Cytosol), compared with vehicle-treated control SFM-5d cells. 
S-ECM increased the nuclear GAPDH levels in $\mathrm{Y}$ HDFs from 5.97 to $14.94 \%$ (\#\#\# $p$ 0.001) and Y-ECM reduced those in S-HDFs from 85.32 to $42.02 \%\left({ }^{\# \#} p<\right.$
0.001). These data suggest that young ECM induces a young phenotype in a portion of senescent cells and consequently changes the distribution of GAPDH.
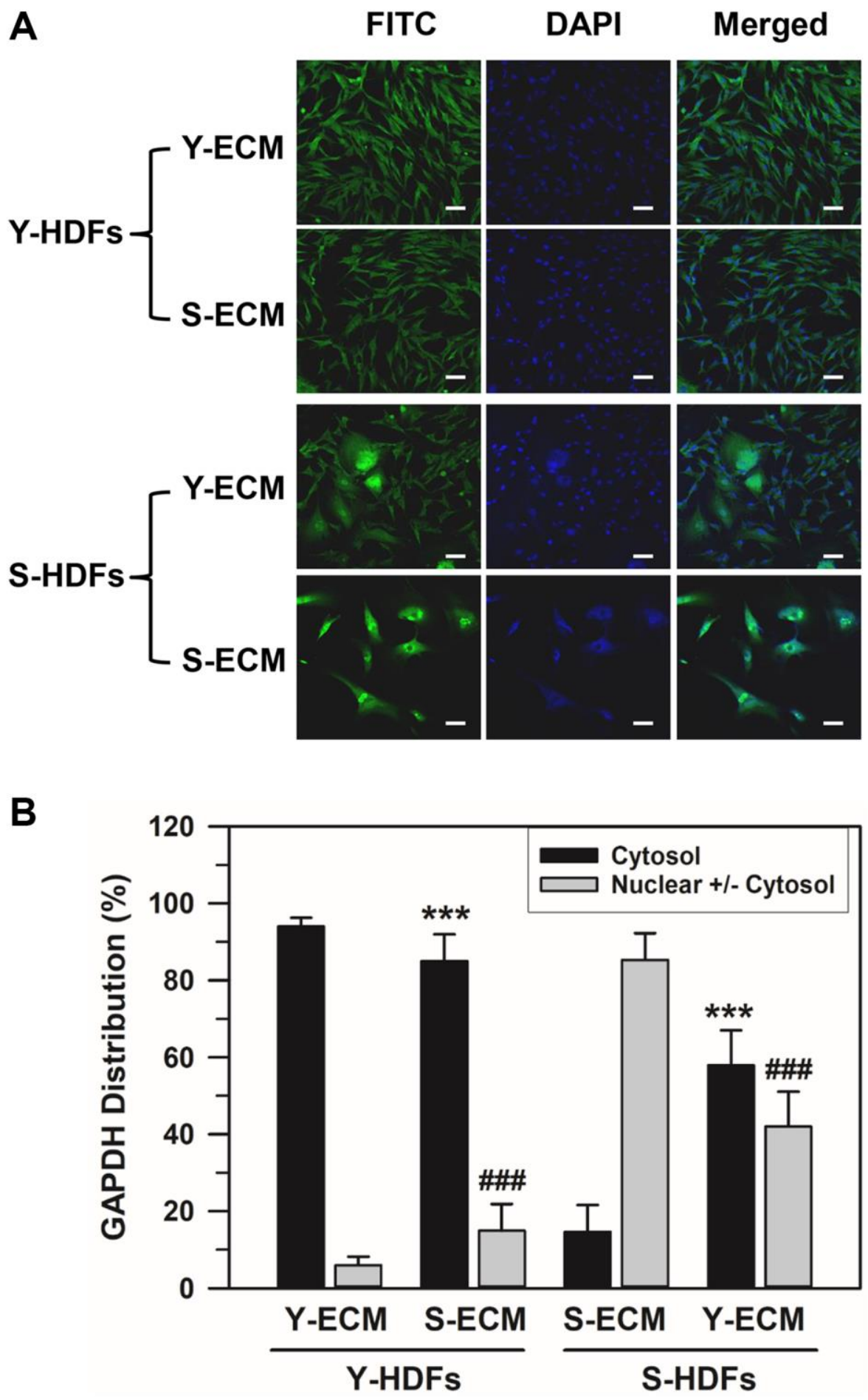

Figure 3. Effect of young ECM on the nuclear localization of GAPDH in senescent HDFs. (A) Young (Y-HDFs, PD 16) and senescent (S-HDFs, PD 75) cells were seeded onto cover slides coated with young ECM (Y-ECM) or senescent ECM (S-ECM). After incubation for 5 days, cells were immunostained against GAPDH and analyzed by confocal laser scanning microscopy (magnification, 100x; scale bar, 50 $\mu$ m). (B) The number of cells with cytosolic GAPDH alone (Cytosol) and cells having nuclear GAPDH with or without cytosolic GAPDH (Nuclear +/Cytosol) was counted, and the percentage distributions were calculated ( $n=18$ for total replicates) and plotted as means \pm standard

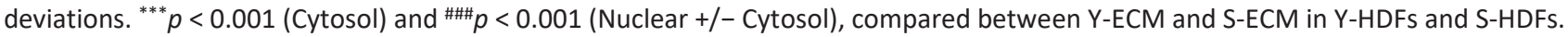




\section{Effect of AMPKa protein and AMPK activity modifiers on GAPDH distribution}

The amount of total $\mathrm{AMPK} \alpha_{1 / 2}$ and phosphorylated AMPK $\alpha_{1 / 2}$ on $\mathrm{Thr}^{172}\left(\mathrm{P}-\mathrm{AMPK} \alpha_{1 / 2}\right)$ in HDFs at different stages (Y: young cells with PD 12, M: middle cells with PD 48, and S: senescent cells with PD 86) were assessed via western blot analysis. The total and phosphorylated AMPK $\alpha$ bands of senescent HDFs after either SFM or $10 \%$ FBS addition were darker than the others (Figure 4A and Supplementary Figure 1), indicating that the amount of total activated AMPK $\alpha_{1 / 2}$ was higher.

Numerous chemical reagents have been utilized in vivo and in vitro to modulate AMPK activity and AMPKdependent cellular functions. The cell-permeable nucleoside 5-aminoimidazole-4-carboxamide-1- $\quad \beta$-Dribofuranoside (AICAR) is one of the most commonly used AMPK agonists. In contrast, the cell-permeable pyrazolopyrimidine derivative 6-[4-(2-Piperidin-1-ylethoxy)-phenyl]-3-pyridin-4-yl-pyrazolo

[1,5-a] pyrimidine (Compound $\mathrm{C}$ : abbreviated to $\mathrm{CompC}$ ) is a potent AMPK blocker via ATP-competitive inhibition. In this study, we used these AMPK activity modifiers. To determine the effects of AICAR and CompC on AMPK activation and GAPDH distribution, subconfluent senescent HDFs were serum-deprived for 2 days and were treated with vehicle, $1 \mathrm{mM}$ AICAR. and/or $10 \mu \mathrm{M}$ CompC for 2 days. Following treatment with AICAR and CompC, the cells were assessed by western blot analysis. The addition of AICAR to senescent HDFs increased AMPK activity, and the activation was negated by the addition of CompC (Figure 4B and Supplementary Figure 2).

The effects of AICAR and CompC were examined using the number of subconfluent senescent HDFs with GAPDH in the cytosol alone (cytosol) or the nucleus, regardless of cytosolic GAPDH (nuclear +/- cytosol). Following treatment with AICAR and CompC, senescent cells were analyzed by immunofluorescence staining and confocal laser scanning microscopy. The number of cells having cytosolic GAPDH only (cytosol) and cells having nuclear GAPDH with or without cytosolic GAPDH (nuclear +/- cytosol) was counted, and the percentage distributions were plotted (Figure 4C). Statistically significant differences between groups were determined by one-way ANOVA $(F(3,156)=$ 220.508, $p<10^{-3}$ ) followed by Dunnett's T3 post hoc test. Compared with HDFs without treatment with AICAR or CompC (-/-), the number of HDFs with cytosolic GAPDH only decreased significantly $\left({ }^{* * *} p<\right.$ 0.001 ) from 20.62 to $7.47 \%$ with the addition of AICAR, but increased significantly $\left({ }^{* * *} p<0.001\right)$ to $43.60 \%$ with the addition of CompC. As expected, the number of HDFs with nuclear GAPDH with or without cytosolic GAPDH increased significantly $\left({ }^{\# \#} p<0.001\right)$ from 79.38 to $92.53 \%$ with the addition of AICAR, but decreased to $56.40 \%$ with the addition of CompC $\left({ }^{\# \#} p\right.$ $<0.001)$. When AICAR and CompC were both added to the medium, the number of HDFs with nuclear GAPDH was significantly reduced, similar to when only CompC was added. These data suggest that AMPK activation might be required for the nuclear translocation of GAPDH in senescent HDFs.

Effects of AMPKa siRNA transfection on the nuclear accumulation of GAPDH in senescent HDFs

We applied an AMPK $\alpha$-specific siRNA approach to support the effect of AMPK $\alpha$ isoforms on the nuclear accumulation of GAPDH in senescent HDFs. Because the major isoforms of the AMPK $\alpha$ subunit in HDFs are AMPK $\alpha_{1}$ and AMPK $\alpha_{2}$, we used a mixture of siRNAs against $\mathrm{AMPK} \alpha_{1}$ and $\mathrm{AMPK} \alpha_{2}$ to block the expression of both isoforms. As depicted in Figure 5A and Supplementary Figure 3, AMPK $\alpha$ siRNA transfection for 48-72 $\mathrm{h}$ reduced the total AMPK $\alpha_{1 / 2}$ protein expression. Moreover, AMPK $\alpha$ siRNA-transfected HDFs presented with increased amounts of cytosolic GAPDH when compared with the control scrambled siRNA duplextransfected HDFs (Figure 5B). AMPK $\alpha_{1 / 2}$ depletion by siRNA treatment significantly prevented the nuclear accumulation of GAPDH compared to the mock siRNA transfection group. Statistically significant differences between groups were determined by one-way ANOVA $\left(F(3,156)=239.297, p<10^{-3}\right)$ followed by Dunnett's T3 post hoc test. The percentage distributions of HDFs with cytosolic GAPDH only for the mock control group were 20.44 and $19.21 \%$ at 48 and $72 \mathrm{~h}$, respectively. In the AMPK $\alpha$ siRNA-transfected cells, these were increased significantly $\left({ }^{* * *} p<0.001\right)$ to 32.55 and $46.68 \%$ at 48 and $72 \mathrm{~h}$, respectively. In contrast, the percentage distribution of HDFs with nuclear GAPDH decreased from 79.56 to $67.45 \%$ at $48 \mathrm{~h}$ and from 80.79 to $53.32 \%$ at $72 \mathrm{~h}\left({ }^{\# \#} p<0.001\right)$. These data support the idea that AMPK activation is responsible for the nuclear accumulation of GAPDH in senescent HDFs.

\section{AICAR- and SFM-induced GAPDH translocation in $A M P K \alpha_{1} / \alpha_{2}$ knockout mouse embryonic fibroblasts MEFs}

Using three types of AMPK $\alpha$-knockout MEFs, AMPK $\alpha_{1}$ null $\left(\alpha_{1}^{-/-}\right)$, AMPK $\alpha_{2}$ null $\left(\alpha_{2}^{-/-}\right)$, and AMPK $\alpha_{1}$ and $\alpha_{2}$ null $\left(\alpha_{1}{ }^{--} \alpha_{2}{ }^{--}\right)$, the effects of the catalytic $\alpha$ subunit of AMPK on GAPDH translocation were assessed. The baseline level of nuclear GAPDH and the level of its nuclear translocation upon addition of $1 \mathrm{mM}$ AICAR or culturing in SFM for $48 \mathrm{~h}$ were compared in control MEFs and AMPK $\alpha$-knockout MEFs. The statistically significant difference between groups was determined by one-way ANOVA $(F(7,72)=242.501$, 
A
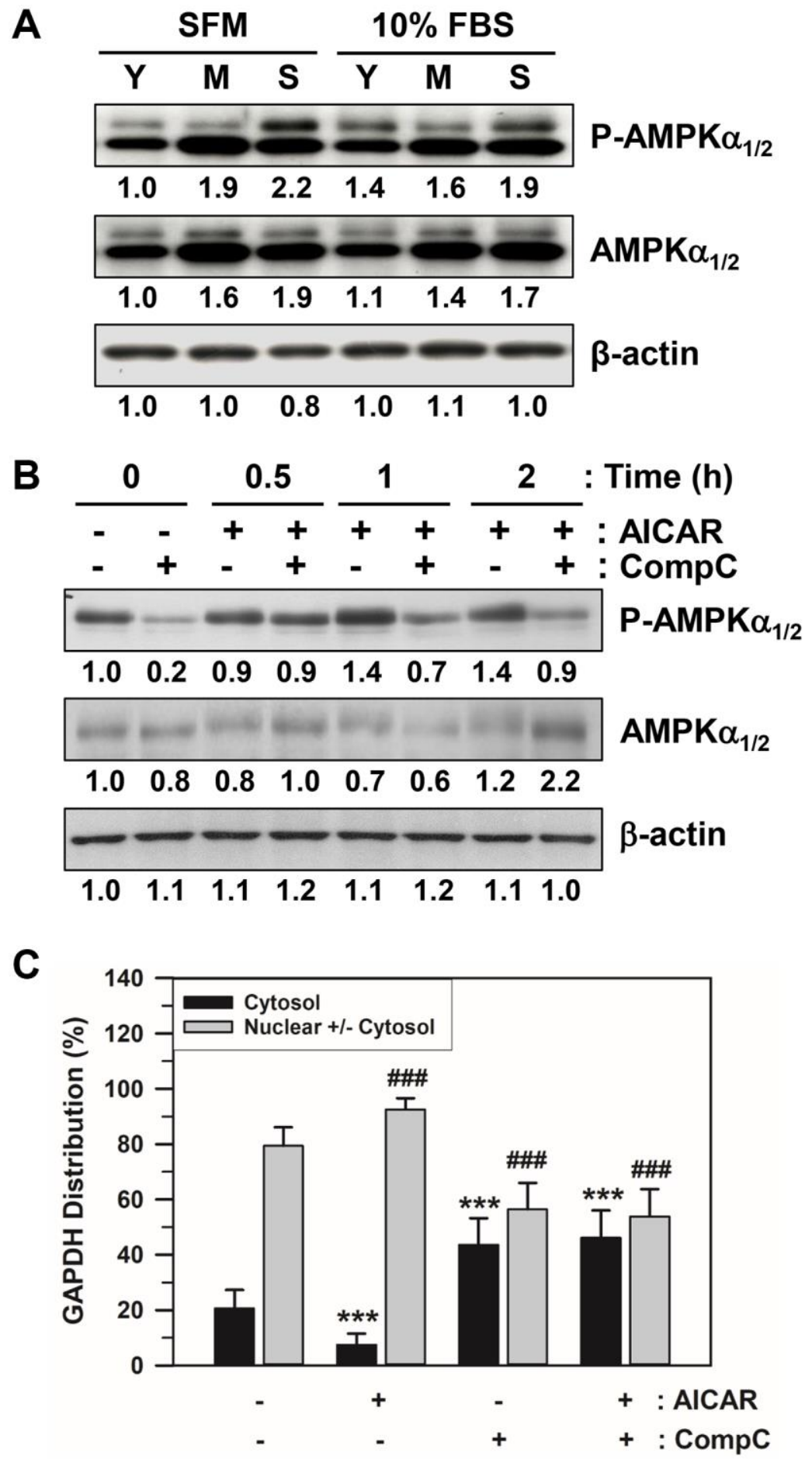

Figure 4. Effects of AICAR and CompC on AMPK activation and GAPDH distribution in senescent HDFs. (A) Subconfluent young (Y, PD 12), middle (M, PD 48), and senescent (S, PD 86) HDFs were incubated with SFM or $10 \%$ FBS medium for 2 days. (B) Subconfluent young (PD 20) and senescent (PD 74) HDFs were treated with vehicle (-) or $1 \mathrm{mM} \mathrm{AICAR}$ and/or $10 \mu \mathrm{M}$ CompC (+) for 2 days. Cells in A and $B$ were lysed in a lysis buffer, and $45 \mu \mathrm{g}$ of protein from each lysate was assessed for the levels of phosphorylated AMPKa1/2 on Thr172 (P-AMPK $\alpha 1 / 2$ ), total AMPK $\alpha 1 / 2$, and $\beta$-actin by western blot analysis. The band densities were normalized against $\beta$-actin and the fold changes compared to that of young cells (Y/SFM) in A and vehicle treated control cells (-/-) in B are written under each band. (C) Subconfluent senescent (PD 72) HDFs were treated with vehicle (-) or $1 \mathrm{mM} \mathrm{AICAR}$ and/or $10 \mu \mathrm{M}$ CompC (+) for 2 days. Cells were immunostained against GAPDH and analyzed by confocal laser scanning microscopy. The number of cells with cytosolic GAPDH alone (Cytosol) and cells having nuclear GAPDH with or without cytosolic GAPDH (Nuclear +/- Cytosol) was counted, and the percentage distributions were calculated ( $n=40$ for total replicates) and plotted as means \pm standard deviations. ${ }^{* * *} p<0.001$ (Cytosol) and ${ }^{\# \# \#<0.001}$ (Nuclear +/- Cytosol), compared with vehicle-treated control cells (-/-). 
A
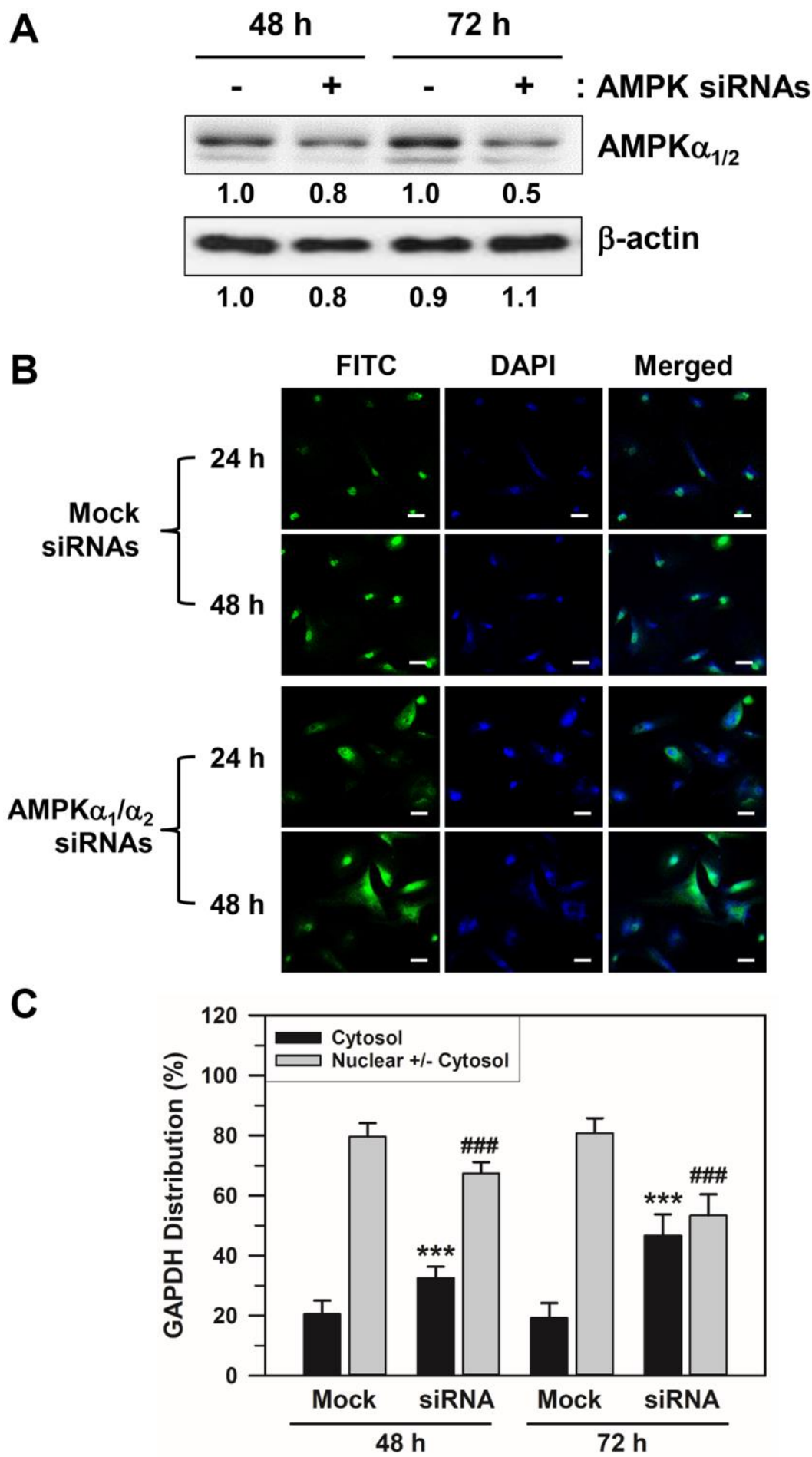

Figure 5. Effects of AMPK $\alpha$ siRNA transfection on the nuclear accumulation of GAPDH in senescent HDFs. Senescent HDFs were transfected with control scrambled siRNA duplexes (-) or siRNAs against AMPK $1 / 2(+)$ for 48 and $72 \mathrm{~h}$ in DMEM with $10 \%$ FBS. (A) Cells were harvested at the indicated times after transfection, and lysates containing the same amount of protein (45 $\mu \mathrm{g}) \mathrm{were}$ assessed by western blot analysis using polyclonal anti-AMPK $\alpha 1 / 2$ and anti- $\beta$-actin antibodies. The band densities were normalized against $\beta$-actin and the fold changes of AMPK $\alpha 1 / 2$ in AMPK $\alpha$ siRNA-transfected cells $(+)$ compared to that of scrambled siRNA-treated control cells (-) are written under each band. (B) Cells were immunostained against GAPDH and analyzed by confocal laser scanning microscopy (magnification, 100x; scale bar, $50 \mu \mathrm{m}$ ). (C) The number of cells with cytosolic GAPDH alone (Cytosol) and cells having nuclear GAPDH with or without cytosolic GAPDH (Nuclear +/- Cytosol) was counted, and the percentage distributions were calculated ( $n=40$ for total replicates) and plotted as means \pm standard deviations. ${ }^{* * *} p<0.001$ (Cytosol) and ${ }^{\# \#} p<0.001$ (Nuclear $+/-$ Cytosol), compared with the mock control siRNA. 
$p<10^{-3}$ ) followed by Dunnett's T3 post hoc test. The control MEFs showed a significant increase in the level of nuclear GAPDH upon AICAR addition to $78.74 \%$ (5.84-fold increase), compared to the basal level of $13.49 \%$ (Figure 6A). Compared to the control MEFs, the baseline levels of nuclear GAPDH were reduced
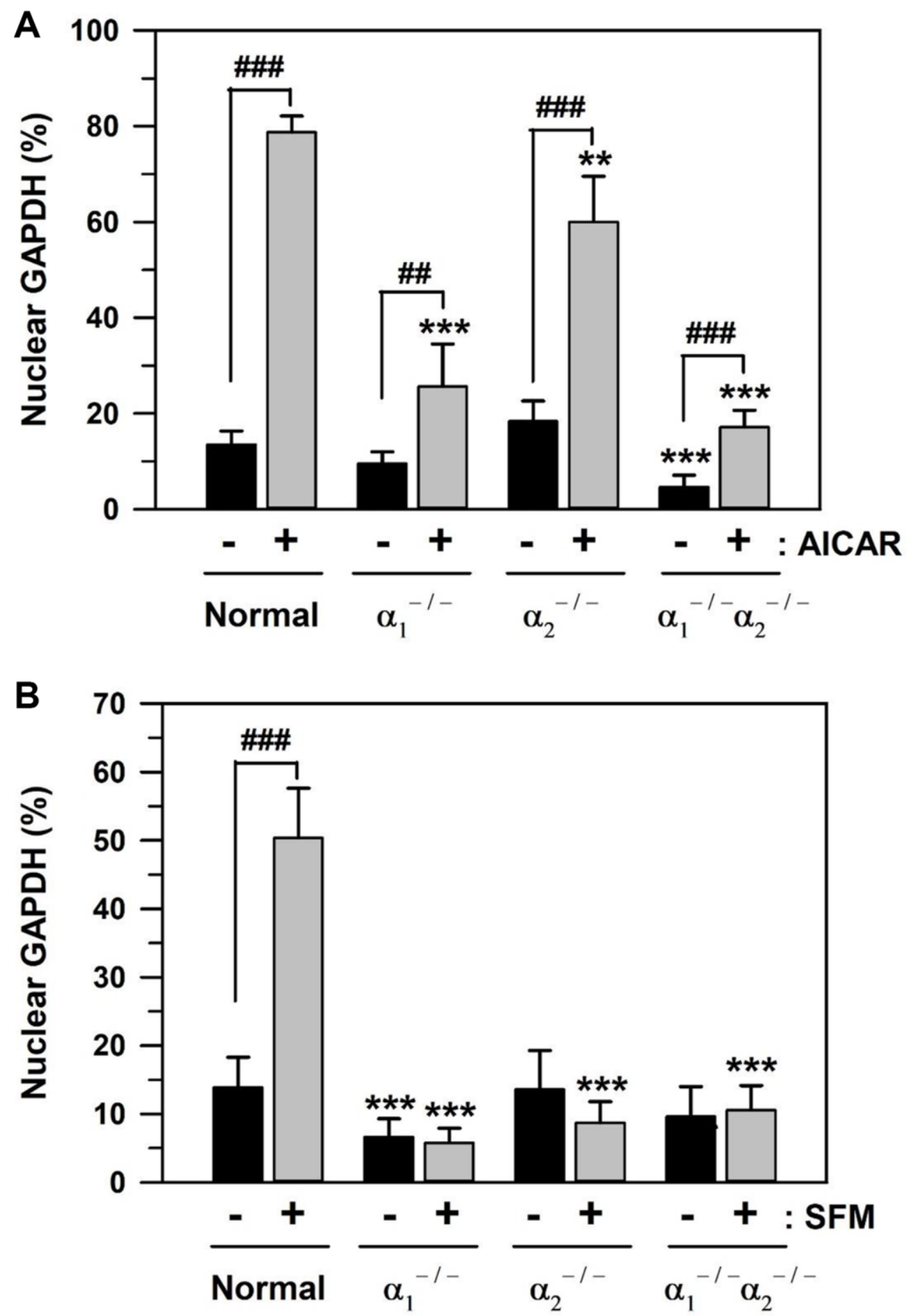

Figure 6. AICAR- and SFM-induced GAPDH translocation in AMPK $\alpha$-knockout MEFs. (A and B) Normal and AMPK $\alpha$-null MEF cells (AMPK $\alpha 1^{-/-}$, AMPK $\alpha 2^{-/-}$, and AMPK $\alpha 1^{-/-} / \alpha 2^{-/-}$) were cultured in $10 \%$ FBS medium for 2 days and then treated with 1 mM AICAR (A) or SFM (B) for 2 days. Cells were immunostained with a GAPDH-specific antibody and analyzed by confocal laser scanning microscopy. The number of cells having nuclear GAPDH with or without cytosolic GAPDH was counted, and the percentage distributions were calculated $(n=10$ and 20 for total replicates in A and B, respectively) and plotted as means +/- standard deviations. ${ }^{* *} p<0.01$ and ${ }^{* * *} p<0.001$, compared with

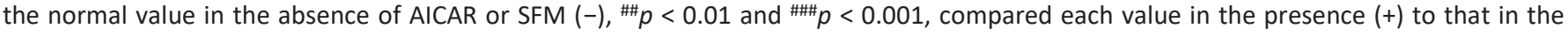
absence of AICAR or SFM (-). 
to 9.53 and $4.63 \%\left({ }^{* * *} p<0.001\right)$ in $\mathrm{AMPK} \alpha_{1}{ }^{-/-}$and AMPK $\alpha_{1}{ }^{-1-} / \alpha_{2}{ }^{-1-}$ MEFs, respectively. The rates of nuclear GAPDH upon AICAR addition significantly

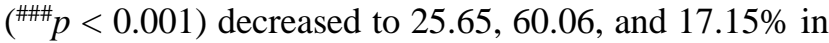
$\mathrm{AMPK} \alpha_{1}{ }^{--}, \mathrm{AMPK} \alpha_{2}{ }^{--}$, and AMPK $\alpha_{1}{ }^{-1-} / \alpha_{2}{ }^{-/-}$MEFs, respectively, compared to $78.74 \%$ in control MEFs. These data indicate the critical role of $\mathrm{AMPK} \alpha_{1}$ and the partial role of $A M P K \alpha_{2}$ in the nuclear translocation of GAPDH in MEFs.

Similar to AICAR, the effect of serum depletion was also examined in the control and three types of AMPK $\alpha$-knockout MEFs. The statistically significant difference between groups in Figure 6B was determined by one-way ANOVA $(F(7,152)=217.107$, $p<10^{-3}$ ) followed by Dunnett's T3 post hoc test.

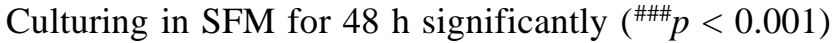
induced nuclear GAPDH from the baseline level of 13.86 to $50.38 \%$ (3.63-fold increase) in control MEFs (Figure 6B). In AMPK $\alpha_{1}{ }^{-/}$MEFs, the baseline levels of nuclear GAPDH were significantly reduced to $6.65 \%\left({ }^{* * *} p<0.001\right)$, compared to $13.86 \%$ of the control MEFs. Furthermore, the levels of nuclear GAPDH in SFM culture significantly $\left({ }^{* * *} p<0.001\right)$ decreased to 5.78, 8.73, and $10.55 \%$ in ${\mathrm{AMPK} \alpha_{1}}^{-1}$, $\mathrm{AMPK} \alpha_{2}{ }^{-1-}$, and AMPK $\alpha_{1}{ }^{-1-} / \alpha_{2}{ }^{-1-}$ MEFs, respectively, compared to $50.38 \%$ in control MEFs (Figure 6B). These results suggest that both AMPK $\alpha_{1}$ and AMPK $\alpha_{2}$ proteins are necessary for SFM-induced GAPDH nuclear translocation.

\section{DISCUSSION}

The intracellular localization of GAPDH is closely related to the diverse functions that GAPDH performs. Particularly, nuclear translocation of GAPDH is necessary for the transcriptional regulation of gene expression, DNA repair, and apoptosis [12-15], and cellular senescence via telomere shortening [16]. Because GAPDH was shown to translocate to the nucleus under various stress conditions, such as serum depletion [50] and oxidative stress [22], aging-associated growth signal deficits and oxidative stress may be involved in GAPDH nuclear translocation. Our present study indicated that GAPDH is distributed mainly in the nucleus in senescent HDFs, compared to young HDFs, and rat back skin cells (Figure 1). Permanent nuclear localization of GAPDH might correlate well with senescent-like growth arrest.

Nuclear localization of GAPDH can be modulated by cellular signaling cascades, including phosphoinositide 3-kinase (PI3K) and AMPK signaling pathways, in HDFs [50] and in pancreatic ductal adenocarcinoma [20]. Growth stimuli activate the PI3K signaling cascade, which leads to the nuclear export of GAPDH translocated by serum depletion, presumably via the activation of AMPK activity, in young HDFs. Therefore, we assumed that the nuclear accumulation of GAPDH in senescent HDFs could be reversed by the re-addition of serum or growth factors, such as PDGF and LPA. However, the age-related GAPDH nuclear deposits were reversed by treatment with LPA, but not PDGF (Figure 2B-2C). PDGF-induced signaling events are dramatically reduced, possibly due to the reduction in PDGF receptor expression, while a decrease in LPA-induced signaling events is less evident with aging [52, 53]. $\mathrm{Li}$ et al. also supported that as HDFs senesce, they become unresponsive to PDGF stimulation [54]. In contrast, LPA increases the proliferation of senescent HDFs by inhibiting AMPK $\alpha$ expression [55]. Hence, the nuclear export of GAPDH with the addition of LPA in our study could be a result of AMPK inhibition.

Furthermore, we found that age-related GAPDH translocation might be reversed by the addition of young ECM (Figure 3). This is consistent with a previous study that found morphologic rejuvenation of senescent cells with the addition of young ECM [9]. We conclude that age-related changes in the ECM include alterations in biochemical and/or biomechanical components that influence the upstream signaling pathway of GAPDH nuclear translocation. The assessment of the specific components involved in age-related changes was beyond the scope of the study and remains as an interesting aspect to explore further.

The dysregulation of ECM composition and structure contributes to several pathological conditions such as fibrosis and invasive cancer [56]. Fibrosis is a common process characterized by excessive ECM accumulation, whereas dynamic remodeling of the ECM around invasive cancer cells is implicated in tumor progression [57]. Accumulating evidence suggests that the PI3K/Akt signaling pathway plays a positive role in the pathological formation of fibrosis [58] and various human cancers [57, 59]. In contrast, AMPK alleviates fibrogenesis and ECM production in various organs and tissues [44]. Metformininduced AMPK activation is indirectly associated with a lower incidence of pancreatic cancer in patients with type 2 diabetes [60]. Metformin inhibited the proliferation of pancreatic stellate cells in the pancreatic tumor stroma and decreased the production of ECM proteins by activating AMPK phosphorylation. As the PI3K/Akt pathway is involved in various biological processes, several on-target and off-target effects may be observed, which can limit the clinical development of 
therapeutics. AMPK activators such as metformin, AICAR, poricoic acid A, and HL156A may function as potential therapeutic agents for both fibrosis and cancer in aging organs [61-65].

Although AMPK activation is thought to delay aging [45], hyperactive AMPK has been linked to agerelated diseases, such as Alzheimer's disease and other cognitive dysfunctions [4, 49]. Therefore, further studies are needed to elucidate the role of AMPK in aging and age-related diseases. Previously, the AMP:ATP ratio and basal AMPK activity were found to increase during cellular senescence [66] in kidney cells and skin cells of aged rats $[55,67]$ and in the liver and brain hippocampus of aged mouse [4, 68]. In other studies, AMPK $\alpha$ phosphorylation and $\mathrm{AMPK} \alpha_{1}$ and $\mathrm{AMPK} \alpha_{2}$ activities were unaltered during aging at rest, but activation of $\mathrm{AMPK} \alpha_{1}$ was enhanced, while activation of $\mathrm{AMPK} \alpha_{2}$ was suppressed immediately after endurance-type muscle contractions in aged rats, resulting in inactive heterotrimer composition of AMPK and consequently increasing skeletal muscle atrophy sarcopenia [69]. In our study, we observed that basal AMPK activity was elevated in senescent HDFs, as indicated by enhanced phosphorylation on $\mathrm{Thr}^{172}$ (Figure 4A). Although the basal activity of AMPK is elevated or unaltered in a context-dependent manner, the responsiveness of AMPK signaling to cellular stresses and an acute or chronic activator of AMPK seems to decline during the aging process $[46,68,70]$. The molecular mechanism of age-related changes in AMPK activation capacity is poorly understood, but its dephosphorylation on $\mathrm{Thr}^{172}$ by phosphatases and inhibitory phosphorylation by kinases in the upstream signaling pathways might also play a role in the modulation of AMPK activation [34, 38].

In the present study, various methods of AMPK activity modification were employed to modulate GAPDH translocation in senescent cells: the AMPK activator AICAR increased GAPDH nuclear translocation, possibly because of higher levels of phosphorylated AMPK, but the AMPK inhibitor CompC induced GAPDH nuclear export (Figure 4C). Interestingly, at an $\mathrm{IC}_{50}$ value of $0.1-0.2 \mu \mathrm{M}$, CompC inhibited AMPK, but the expression of a few other protein kinases, such as ERK8 and PDGF receptor tyrosine kinase, were also inhibited with similar or greater potency $[71,72]$. Moreover, the effect of CompC and its mechanism of action depend on the cell type and context $[73,74]$; therefore, the validity of CompC as an AMPK blocker should be further assessed. Moreover, the PI3K/Akt pathway has been implicated in the regulation of nuclear translocation of GAPDH [50]. Because AICAR inhibits the
PI3K/Akt signaling pathway in an AMPK-dependent manner [75] or AMPK-independent manner [76], AICAR may partly affect the PI3K and downstream Akt signaling pathways in a negative manner. Moreover, the addition of AICAR leads to AMPK activation along with Akt dephosphorylation, which suggests a coordinated inverse regulation of AMPK and Akt [77, 78]. Some growth signals or chemicals that activate the PI3K/Akt pathway could reverse the senescence-associated nuclear localization of GAPDH, presumably rejuvenating senescent cells. LPA and young ECM may stimulate mitogenic signals, such as PI3K and Akt, to a limited degree in senescent cells $[52,53]$. Therefore, future studies of the molecular mechanisms underlying GAPDH nuclear translocation besides via AMPK-dependent phosphorylation are necessary to understand this phenomenon.

The role of AMPK protein expression in GAPDH translocation was also confirmed by AMPK $\alpha_{1} / \alpha_{2}$ siRNA transfection and utilization of AMPK $\alpha$-knockout MEFs, AMPK $\alpha_{1}$ null $\left(\alpha_{1}^{--}\right)$, AMPK $\alpha_{2}$ null $\left(\alpha_{2}^{--}\right)$, and AMPK $\alpha_{1} / \alpha_{2}$ null $\left(\alpha_{1}^{-l-} \alpha_{2}{ }^{--}\right)$. AMPK $\alpha$ depletion by $\mathrm{AMPK} \alpha_{1 / 2}$ siRNA transfection reduced $\mathrm{AMPK} \alpha_{1 / 2}$ protein levels (Figure 5A) and reduced nuclear accumulation of GAPDH in senescent HDFs (Figure $5 \mathrm{~B}, 5 \mathrm{C})$. Although the basal levels of nuclear GAPDH were changed differently in AMPK $\alpha_{1^{-}}$and $\mathrm{AMPK} \alpha_{2}-$ knockout MEFs, the levels of nuclear GAPDH translocated upon AICAR and SFM addition were reduced in both $\mathrm{AMPK} \alpha_{1}$-knockout and $\mathrm{AMPK} \alpha_{2}-$ knockout MEFs (Figure 6A and 6B, respectively). These results suggest that both AMPK $\alpha_{1}$ and AMPK $\alpha_{2}$ proteins are necessary for AICAR- and SFM-induced GAPDH nuclear translocation.

At present, the role of the AMPK-dependent translocation of GAPDH in senescent cells has not been elucidated. The effect of AMPK activation differs depending on the type of cell or tissue and the type and duration of the damaging agent. AMPK activation and AICAR treatment significantly inhibited the proliferation of various cell lines and cancer cells via cell cycle arrest, accompanied by the increased expression of $\mathrm{p} 21, \mathrm{p} 27$, and $\mathrm{p} 53$ proteins and inhibition of the PI3K/Akt pathway [79]. Conversely, the proliferation potential of senescent HDFs can be increased by inhibiting the AMPK signaling pathway [55]. AMPK also contributes to UV- and $\mathrm{H}_{2} \mathrm{O}_{2}$ induced apoptosis in human skin keratinocytes by inhibiting mTOR and positively regulating p53 and p38 expression [80]. AMPK activation by AICAR treatment induces apoptosis in B-cell chronic lymphocytic leukemia cells [81], retinoblastoma cells [82], and rat pituitary tumor cells [83]. Moreover, 
AMPK is required for the pro-apoptotic effects of quercetin in non-malignant cells as well as in various tumor cells [84]. In contrast, the AMPK pathway plays a protective role against insult-induced apoptosis. For example, AMPK activation reduces anoxia-induced apoptosis [85] and high glucose-induced apoptosis in HUVECs [86], presumably through the regulation of autophagy [36]. AMPK activation is also an essential component of the adaptive response to cardiomyocyte stress that occurs during myocardial ischemia [47]. Therefore, pharmacological activation of AMPK can be applied as a cardioprotective strategy for the treatment of myocardial infarction [48]. Depending on the presence of downstream targets of AMPK, such as mTOR, SIRT1, Nrf2, NF-кB, PI3K/Akt, and p38 MAPK, AMPK can exert opposite functions in different cells.

The effect of nuclear GAPDH also depends on the type of cell and insult. Nuclear GAPDH induces apoptosis triggered by various cytotoxic stressors [87-90]. The mechanism underlying GAPDH translocation and subsequent cell death is related to several protein factors such as SIRT1, p53, Bcl-2, and Siah1 [90]. Mutant p53, predominantly found in various aggressive cancer cells, prevents GAPDH translocation, supports glycolysis in cancer cell growth, and inhibits cell death mediated by nuclear GAPDH [20]. Phosphorylation of GAPDH at Ser122 by AMPK, S-nitrosylation, S-glutathionylation, acetylation, and Siah1 binding to GAPDH are required for the nuclear translocation of the enzyme $[19,23,26,27]$. Phosphorylation by Src and Akt2, SIRT1 expression by mutant p53, and subsequent deacetylation by SIRT1 in the cytoplasm prevent GAPDH translocation [24]. Under oxidative conditions, oxidized GAPDH is translocated to the nucleus to form aggregates, which act as a seed to accelerate amyloidogenesis, resulting in apoptosis and neurodegenerative diseases $[22,28]$. In contrast, nuclear GAPDH also exhibits cytoprotective effects by participating in various cellular events such as autophagy and DNA repair $[14,21]$. Whatever way they work, AMPK-dependent nuclear translocation of GAPDH seems to play an important role in the fate of senescent cells and in age-related diseases.

Taken together, our results, summarized in Figure 7, suggest that the nuclear accumulation of GAPDH might be due to enhanced AMPK activity in senescent HDFs, which could possibly be reversed with proper modification of AMPK activity.

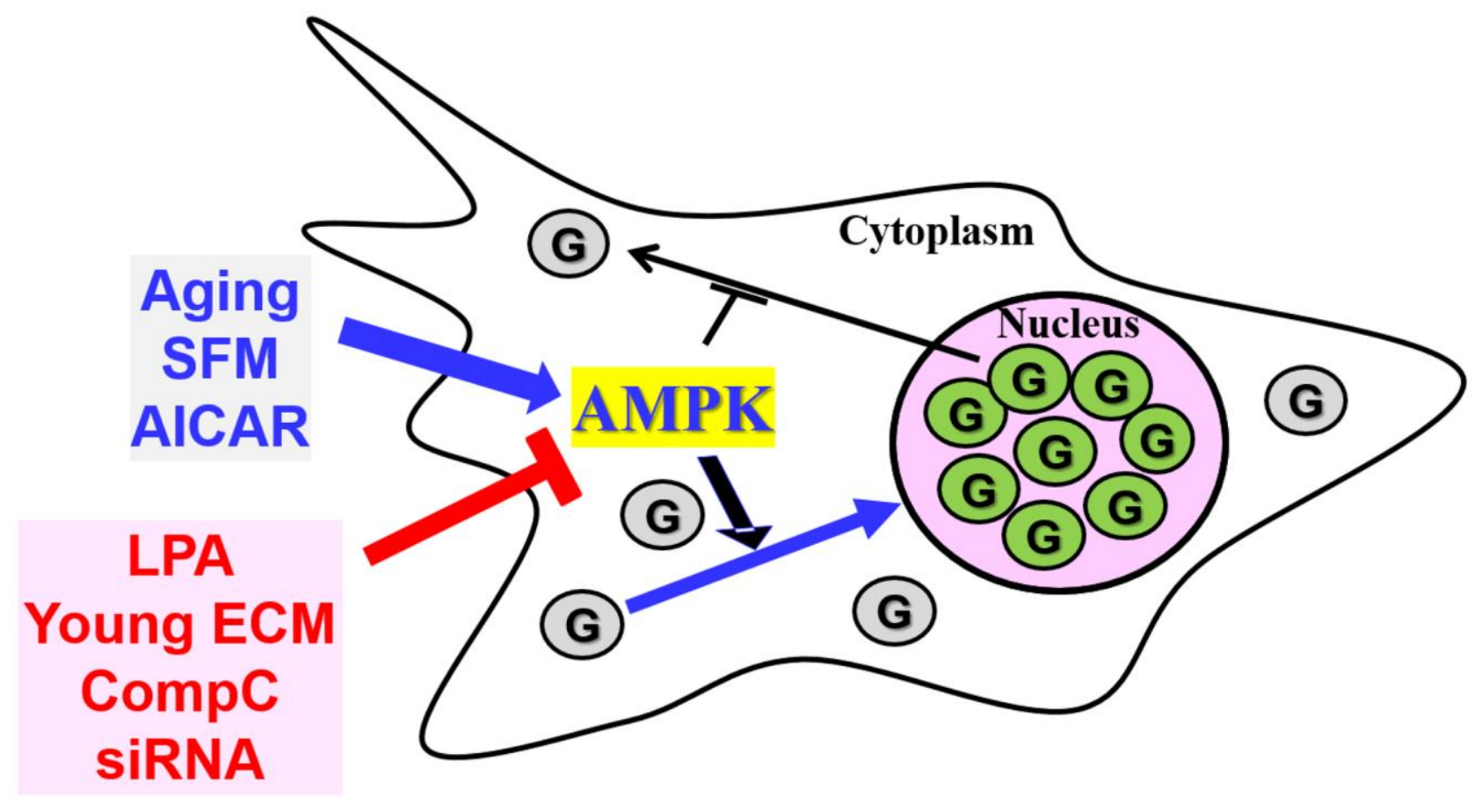

Figure 7. The AMPK signal transduction pathway is involved in the nuclear translocation of GAPDH in senescent HDFs. GAPDH (G) is present mainly in the nucleus of senescent HDFs and other cells from aged animals. When senescent cells are serum-depleted by incubation with SFM or treated with the AMPK activator AICAR, which may result in AMPK activation, GAPDH translocates completely to the nucleus. AMPK inhibition by LPA, young ECM, CompC and AMPKa-siRNAs prevents basal and SFM- or AICAR-induced nuclear translocation of GAPDH. Taken together, the nuclear accumulation of GAPDH in senescent cells can be altered by the modulation of AMPK $\alpha$ expression and activation. 


\section{MATERIALS AND METHODS}

\section{Materials}

PDGF-BB, LPA, fluorescein isothiocyanate (FITC)conjugated goat anti-mouse secondary antibody (\#F0257), and mouse anti- $\beta$-actin monoclonal antibody (\#A5441) were purchased from Sigma-Aldrich (St. Louis, MO, USA). Dulbecco's modified Eagle's medium (DMEM), FBS, opti-MEM I, penicillin, and streptomycin were obtained from Gibco/BRL Life Technologies, Inc (Carlsbad, CA, USA). Rabbit monoclonal antibodies against AMPK $\alpha(\# 2532 S)$ and phospho-Thr ${ }^{172}$-AMPKa (40H9: \#2535S), and rabbit monoclonal anti-GAPDH $\operatorname{IgG}(\# 2118 \mathrm{~S})$ for immunohistochemistry were purchased from Cell Signaling Technology (Denver, MA, USA). CompC and AICAR were purchased from Calbiochem (San Diego, CA, USA) and mouse anti-GAPDH monoclonal antibody (\#MAB374) was from Chemicon (Bedford, MA). Horseradish peroxidase-conjugated anti-rabbit (\#PI-1000) and anti-mouse (\#PI-2000) secondary antibodies were obtained from Vector Laboratories (Burlingame, CA, USA) and protein assay kit was from Bio-Rad Laboratories (Hercules, CA, USA). Trypsin and Zymed Picture Plus Kit was purchased from Zymed (South San Francisco, CA, USA), and predesigned human AMPK $\alpha_{1 / 2}$-specific and control scrambled siRNA duplexes were purchased from Santa Cruz Biotechnology (Santa Cruz, CA, USA). Lipofectamine $^{\mathrm{TM}}$, RNAiMAX, and Permount mounting solution including 4',6-diamidino-2-phenylindole (DAPI) were obtained from Invitrogen Life Technologies (Carlsbad, CA, USA) and enhanced chemiluminescence (ECL) system was from GE Healthcare (Buckinghamshire, UK, USA).

\section{Cell culture}

HDFs were isolated from the foreskin of neonates, as described previously [91]. HDFs were cultured in DMEM supplemented with 10\% FBS, $100 \mathrm{U} / \mathrm{mL}$ penicillin, and $100 \mu \mathrm{g} / \mathrm{mL}$ streptomycin in $100 \mu \mathrm{mm}$ tissue culture dishes and were maintained in a humidified $5 \% \mathrm{CO}_{2}$ incubator at $37^{\circ} \mathrm{C}$. The cells were divided into three groups depending on the duration of growth: young, middle, and senescent. Young HDFs were cultured until PD was less than 25, middle HDFs until PD between 45 and 65, and senescent HDFs until PD greater than 65. Senescent HDFs were identified by their characteristic morphological changes, enhanced beta-galactosidase activity, and cell growth arrest. Before serum depletion, regardless of their classification, HDFs were grown for 2 days to reach 60 $70 \%$ confluency in a culture medium containing $10 \%$ FBS. To determine the effect of serum or growth factor re-addition on the nuclear localization of GAPDH, subconfluent senescent HDFs were serum-deprived via a 5-day-incubation in SFM containing $0.1 \%$ bovine serum albumin (BSA).

\section{Immunofluorescence staining}

For immunofluorescence staining, $1.0 \times 10^{5} \mathrm{HDFs}$ were cultured on coverslips in 6-well culture plates for 1 day and treated with the indicated medium or reagents for the indicated times. The cells on coverslips were washed twice with ice-cold phosphatebuffered saline (PBS), fixed with $4 \%$ paraformaldehyde in PBS for $10 \mathrm{~min}$, and washed with PBS. Subsequently, blocking solution with $2 \%$ BSA in Tris-buffered saline with Tween 20 (TBST: $20 \mathrm{mM}$ Tris, $138 \mathrm{mM} \mathrm{NaCl}, 0.1 \%$ Tween 20, pH 7.4) was used to saturate non-specific protein binding sites for $1 \mathrm{~h}$ with gentle shaking. The cells were incubated with primary monoclonal anti-GAPDH antibody (1:500 1,000 in blocking solution) for $1 \mathrm{~h}$ at $25^{\circ} \mathrm{C}$, and were washed three times with ice-cold TBST for $10 \mathrm{~min}$ each. Cells were incubated with FITCconjugated anti-mouse secondary antibody (1:500) in blocking solution for $30 \mathrm{~min}$. Cells were washed three times with TBST for $10 \mathrm{~min}$ each, and were dehydrated in three washes with $100 \%$ methanol for $1 \mathrm{~h}$. The coverslips were mounted on glass slides with a mounting solution containing DAPI for nuclear staining, and fluorescence images were captured with a confocal laser scanning microscope (FV500; Olympus, Tokyo, Japan). GAPDH was indicated by FITC fluorescence, which glows in green. Blue DAPIstained nuclei and merged images are also visible in confocal microscopic pictures. Each sample was counted in 10-20 different fields at 100x magnification. The data were combined to calculate the total cell number of approximately 100 and were converted to percentage distribution. All experiments were repeated at least three times to obtain reliable statistical inferences.

\section{Transfection of human AMPKa siRNAs}

Senescent HDFs were transfected with $50 \mathrm{nM}$ human AMPK $\alpha_{1 / 2}$-specific or control scrambled siRNA duplexes, as described previously [50]. Briefly, $2.0 \times 10^{4}$ senescent HDFs per well were seeded in 6well plates in $2 \mathrm{~mL}$ of antibiotic-free culture medium supplemented with FBS. Cells were incubated at $37^{\circ} \mathrm{C}$ in a $\mathrm{CO}_{2}$ incubator overnight until the cells were 30 $50 \%$ confluent. The mixture of 50 pmol siRNA duplex in $100 \mu \mathrm{L}$ of Opti-MEM I reduced serum medium and 2 $\mu \mathrm{L}$ of Lipofectamine ${ }^{\mathrm{TM}}$ RNAiMAX transfection reagent were preincubated at room temperature for $15 \mathrm{~min}$ and then diluted in $1 \mathrm{~mL}$ of transfection medium. The 
mixtures were overlaid onto the washed cells. After $6 \mathrm{~h}$ of transfection at $37^{\circ} \mathrm{C}$ in a $\mathrm{CO}_{2}$ incubator, $1 \mathrm{ml}$ of DMEM containing 20\% FBS and $2 \times$ antibiotics was added to each well, and cells were incubated for an additional $24 \mathrm{~h}$ at $37^{\circ} \mathrm{C}$. After refreshing the culture medium to DMEM containing $10 \%$ FBS and $1 \times$ antibiotics, cells were incubated for $48-72 \mathrm{~h}$ and assayed for $\mathrm{AMPK} \alpha_{1 / 2}$ levels using western blot analysis and for GAPDH localization using immunofluorescence staining and confocal microscopy.

\section{Western blot analysis}

Protein expression levels were examined by western blot analysis, as described previously [72]. A total of 1 $\times 10^{6} \mathrm{HDFs}$ grown in 100 -mm culture dish were lysed in lysis buffer $(50 \mathrm{mM}$ Tris- $\mathrm{HCl}, \mathrm{pH} 7.5,150 \mathrm{mM}$ $\mathrm{NaCl}, 2 \mathrm{mM}$ EDTA, $1 \mathrm{mM}$ EGTA, $1 \mathrm{mM} \mathrm{Na} \mathrm{VO}_{4}$, $10 \mathrm{mM}$ NaF, $1 \mathrm{mM}$ DTT, $1 \mathrm{mM}$ PMSF, $25 \mu \mathrm{g} / \mathrm{mL}$ leupeptin, $25 \mu \mathrm{g} / \mathrm{mL}$ aprotinin, $5 \mathrm{mM}$ benzamidine, and $1 \%$ Ingepal CA630) at $4{ }^{\circ} \mathrm{C}$ for $30 \mathrm{~min}$ on a rocker. The lysates were centrifuged at $14,000 \times g$ for $15 \mathrm{~min}$ in an Eppendorf centrifuge to remove cell debris, and the protein concentration of each lysate was determined using a Bio-Rad protein assay kit, according to the manufacturer's protocol. Cell lysates of equal amounts of protein were resolved by sodium dodecyl sulfate-polyacrylamide gel electrophoresis (SDS-PAGE), and transferred electrophoretically onto Immobilon PVDF membranes. A solution containing $5 \%$ non-fat dried milk or $1 \%$ BSA in TBST buffer was used to block the blots for $1 \mathrm{~h}$ at $25^{\circ} \mathrm{C}$. Moreover, proteins were incubated overnight with monoclonal antibody (1:200 to $1: 1000)$ in the blocking solution at $4^{\circ} \mathrm{C}$, washed three times with TBST, and further probed with horseradish peroxidase-conjugated antirabbit secondary IgG (1:5000) for $30 \mathrm{~min}$. An ECL detection system was used to visualize the immune complexes on the blots.

\section{Rat skin section preparation and immunohistochemistry}

Adult male Fisher 344 rats were purchased from Samtaco BioKorea (Seoul, Korea). The animal study was approved by the Institutional Animal Care and Use Committee (IACUC) of the Korea Basic Science Institute (KBSI) (KBSI-ACE1913). The animals were housed two per cage in a room with controlled temperature and humidity with a 12-h light/12-h dark cycle. They were maintained on a standard diet with food and water ad libitum in an animal facility approved by the Korean Association for Assessment and Accreditation of Laboratory Animal Care. The back skin sections of young (6 months) and aged (24 months) rats were obtained as described previously [92]. Rats were anesthetized with an intraperitoneal injection of ketamine and xylazine $(87 / 13 \mathrm{mg} / \mathrm{kg})$. The back was shaved, and a 5-mm-thick skin section was cut. The sections were fixed overnight in ice-cold $10 \%$ paraformaldehyde and embedded in paraffin. Serial paraffin sections on the microslides were deparaffinized in xylene and rehydrated sequentially with ethanol solutions of different grades. Antigens were retrieved by incubation with $10 \mathrm{mM}$ citrate buffer ( $\mathrm{pH} \mathrm{6.0)}$ for 15 min in a $700 \mathrm{~W}$ microwave. Slides were treated with $3 \%$ hydrogen peroxide to inhibit endogenous peroxidase activity and were washed with $0.05 \mathrm{M}$ Tris-buffered saline ( $\mathrm{pH}$ 7.6). The slides were incubated in 5\% skim milk for $1 \mathrm{~h}$ at $25^{\circ} \mathrm{C}$ to block nonspecific binding sites and then incubated overnight with primary rabbit monoclonal anti-GAPDH antibodies $(1: 500)$ at $4^{\circ} \mathrm{C}$. The avidin-biotin peroxidase complex method was used to visualize the immune complex, which was counterstained with hematoxylin and eosin (H\&E). After sequential dehydration using ethanol and xylene, the slides were mounted using Permount. The slides were photographed using a light microscope $(\times 200)$. Each experiment was performed three times.

\section{Statistical analysis}

For statistical analyses of the data, one-way analysis of variance (ANOVA) followed by Dunnett T3 post hoc test (SPSS, IBM, Seoul, Korea) was performed to assess significant differences between groups. Data are presented as the mean \pm standard deviation of at least three experiments. $P$ values of less than 0.05 were considered statistically significant.

\section{Abbreviations}

AICAR: $\quad$ 5-aminoimidazole-4-carboxamide-1- $\beta$-Dribofuranoside; AMPK: AMP-activated protein kinase; CompC: $\quad$ 6-[4-(2-Piperidin-1-yl-ethoxy)-phenyl]-3pyridin-4-yl-pyrazolo [1,5-a] pyrimidine; ECM: extracellular matrix; FBS: fetal bovine serum; FITC: fluorescein isothiocyanate; GAPDH: glyceraldehyde-3phosphate dehydrogenase; HDF: human diploid fibroblast; LPA: lysophosphatidic acid; PDGF: plateletderived growth factor; PI3K: phosphoinositide 3-kinase; SFM: serum free medium.

\section{AUTHOR CONTRIBUTIONS}

JY Sohn, HJ Kwak, and JH Rhim performed the experiments, including cell culture, immunohistochemistry, immunofluorescence staining, western blot analysis, and siRNA transfection, and analyzed the data; JY Sohn wrote a part of the primary manuscript; EJ Yeo designed the experiments, supplied materials, created the figures, and wrote the final version of the manuscript. 


\section{ACKNOWLEDGMENTS}

The authors thank to Dr. Benoit Viollet for the gift of mouse AMPK $\alpha$-wild type and knockout MEFs and IkSoon Jang for providing the back skin sections of young and aged rats. We thank Gachon University for awarding Graduate Students Scholarship Council training grant. Hyeok Jin Kwak is a recipient of the training grant.

\section{CONFLICTS OF INTEREST}

The authors declare no conflicts of interest related to this study.

\section{FUNDING}

This study was supported by the Basic Science Research Program through the National Research Foundation of Korea (NRF) grants to E-J Yeo (Nos. 2017R1D1A1B03033499 and 2020R1F1A1072202) funded by the Ministry of Science and Technology of the Korean Government.

\section{REFERENCES}

1. Harley CB, Futcher AB, Greider CW. Telomeres shorten during ageing of human fibroblasts. Nature. 1990; 345:458-60. https://doi.org/10.1038/345458a0 PMID:2342578

2. López-Otín C, Blasco MA, Partridge L, Serrano M, Kroemer G. The hallmarks of aging. Cell. 2013; 153:1194-217.

https://doi.org/10.1016/i.cell.2013.05.039 PMID:23746838

3. Tidwell TR, Søreide K, Hagland HR. Aging, Metabolism, and Cancer Development: from Peto's Paradox to the Warburg Effect. Aging Dis. 2017; 8:662-76. https://doi.org/10.14336/AD.2017.0713 PMID:28966808

4. Wang BZ, Yang JJ, Zhang H, Smith CA, Jin K. AMPK Signaling Regulates the Age-Related Decline of Hippocampal Neurogenesis. Aging Dis. 2019; 10:1058-74.

https://doi.org/10.14336/AD.2019.0102 PMID:31595203

5. Stambler I, Jin K, Lederman S, Barzilai N, Olshansky SJ, Omokaro E, Barratt J, Anisimov VN, Rattan S, Yang S, Forster M, Byles J. Aging Health and R\&D for Healthy Longevity Must Be Included into the WHO Work Program. Aging Dis. 2018; 9:331-3. https://doi.org/10.14336/AD.2017.1120 PMID:29896422
6. Wang Y, Ji X, Leak RK, Chen F, Cao G. Stem cell therapies in age-related neurodegenerative diseases and stroke. Ageing Res Rev. 2017; 34:39-50.

https://doi.org/10.1016/j.arr.2016.11.002 PMID:27876573

7. Levi N, Papismadov N, Solomonov I, Sagi I, Krizhanovsky V. The ECM path of senescence in aging: components and modifiers. FEBS J. 2020; 287:2636-46. https://doi.org/10.1111/febs.15282 PMID: $\underline{32145148}$

8. Conboy IM, Conboy MJ, Wagers AJ, Girma ER, Weissman IL, Rando TA. Rejuvenation of aged progenitor cells by exposure to a young systemic environment. Nature. 2005; 433:760-4. https://doi.org/10.1038/nature03260 PMID: 15716955

9. Choi HR, Cho KA, Kang HT, Lee JB, Kaeberlein M, Suh Y, Chung IK, Park SC. Restoration of senescent human diploid fibroblasts by modulation of the extracellular matrix. Aging Cell. 2011; 10:148-57.

https://doi.org/10.1111/j.1474-9726.2010.00654.x PMID:21108727

10. Ozcebe SG, Bahcecioglu G, Yue XS, Zorlutuna P. Effect of cellular and ECM aging on human iPSC-derived cardiomyocyte performance, maturity and senescence. Biomaterials. 2021; 268:120554. https://doi.org/10.1016/j.biomaterials.2020.120554 PMID: $\underline{3296796}$

11. Li H, Bao M, Nie Y. Extracellular matrix-based biomaterials for cardiac regeneration and repair. Heart Fail Rev. 2021; 26:1231-48.

https://doi.org/10.1007/s10741-020-09953-9 PMID: 32306220

12. Nakajima $H$, Kubo $T$, Ihara $H$, Hikida $T$, Danjo $T$, Nakatsuji M, Shahani N, Itakura M, Ono Y, Azuma YT, Inui T, Kamiya A, Sawa A, Takeuchi T. Nuclear-translocated Glyceraldehyde-3-phosphate Dehydrogenase Promotes Poly(ADP-ribose) Polymerase-1 Activation during Oxidative/Nitrosative Stress in Stroke. J Biol Chem. 2015; 290:14493-503.

https://doi.org/10.1074/jbc.M114.635607 PMID:25882840

13. Dando I, Pacchiana R, Pozza ED, Cataldo I, Bruno S, Conti P, Cordani M, Grimaldi A, Butera G, Caraglia M, Scarpa A, Palmieri M, Donadelli M. UCP2 inhibition induces ROS/Akt/mTOR axis: Role of GAPDH nuclear translocation in genipin/everolimus anticancer synergism. Free Radic Biol Med. 2017; 113:176-89. https://doi.org/10.1016/j.freeradbiomed.2017.09.022 PMID:28962872

14. Kosova AA, Khodyreva SN, Lavrik OI. Role of Glyceraldehyde-3-Phosphate Dehydrogenase (GAPDH) in DNA Repair. Biochemistry (Mosc). 2017; 82:643-54. 
https://doi.org/10.1134/S0006297917060013 PMID:28601074

15. Hara MR, Agrawal N, Kim SF, Cascio MB, Fujimuro M, Ozeki Y, Takahashi M, Cheah JH, Tankou SK, Hester LD, Ferris CD, Hayward SD, Snyder SH, Sawa A. S-nitrosylated GAPDH initiates apoptotic cell death by nuclear translocation following Siah1 binding. Nat Cell Biol. 2005; 7:665-74.

https://doi.org/10.1038/ncb1268

PMID:15951807

16. Nicholls C, Pinto AR, Li H, Li L, Wang L, Simpson R, Liu JP. Glyceraldehyde-3-phosphate dehydrogenase (GAPDH) induces cancer cell senescence by interacting with telomerase RNA component. Proc Natl Acad Sci U S A. 2012; 109:13308-13. https://doi.org/10.1073/pnas.1206672109 PMID:22847419

17. Sirover MA. Subcellular dynamics of multifunctional protein regulation: mechanisms of GAPDH intracellular translocation. J Cell Biochem. 2012; 113:2193-200.

https://doi.org/10.1002/icb.24113 PMID:22388977

18. Schmitz HD. Reversible nuclear translocation of glyceraldehyde-3-phosphate dehydrogenase upon serum depletion. Eur J Cell Biol. 2001; 80:419-27. https://doi.org/10.1078/0171-9335-00174 PMID:11484933

19. Ventura M, Mateo F, Serratosa J, Salaet I, Carujo S, Bachs O, Pujol MJ. Nuclear translocation of glyceraldehyde-3-phosphate dehydrogenase is regulated by acetylation. Int J Biochem Cell Biol. 2010; 42:1672-80.

https://doi.org/10.1016/i.biocel.2010.06.014 PMID:20601085

20. Butera G, Pacchiana R, Mullappilly N, Margiotta M, Bruno S, Conti P, Riganti C, Donadelli M. Mutant p53 prevents GAPDH nuclear translocation in pancreatic cancer cells favoring glycolysis and 2-deoxyglucose sensitivity. Biochim Biophys Acta Mol Cell Res. 2018; 1865:1914-23.

https://doi.org/10.1016/i.bbamcr.2018.10.005 PMID: 30296496

21. Chang $C$, Su H, Zhang D, Wang $Y$, Shen $Q$, Liu B, Huang R, Zhou T, Peng C, Wong CC, Shen HM, LippincottSchwartz J, Liu W. AMPK-Dependent Phosphorylation of GAPDH Triggers Sirt1 Activation and Is Necessary for Autophagy upon Glucose Starvation. Mol Cell. 2015; 60:930-40. https://doi.org/10.1016/i.molcel.2015.10.037 PMID:26626483

22. Gerszon J, Rodacka A. Oxidatively modified glyceraldehyde-3-phosphate dehydrogenase in neurodegenerative processes and the role of low molecular weight compounds in counteracting its aggregation and nuclear translocation. Ageing Res Rev. 2018; 48:21-31.

https://doi.org/10.1016/j.arr.2018.09.003

PMID:30254002

23. Mustafa Rizvi SH, Shao D, Tsukahara Y, Pimentel DR, Weisbrod RM, Hamburg NM, McComb ME, Matsui R, Bachschmid MM. Oxidized GAPDH transfers Sglutathionylation to a nuclear protein Sirtuin-1 leading to apoptosis. Free Radic Biol Med. 2021; 174:73-83. https://doi.org/10.1016/j.freeradbiomed.2021.07.037 PMID: $\underline{34332079}$

24. Joo HY, Woo SR, Shen YN, Yun MY, Shin HJ, Park ER, Kim SH, Park JE, Ju YJ, Hong SH, Hwang SG, Cho MH, Kim J, Lee KH. SIRT1 interacts with and protects glyceraldehyde-3-phosphate dehydrogenase (GAPDH) from nuclear translocation: implications for cell survival after irradiation. Biochem Biophys Res Commun. 2012; 424:681-6.

https://doi.org/10.1016/j.bbrc.2012.07.006 PMID:22789853

25. Tristan CA, Ramos A, Shahani N, Emiliani FE, Nakajima $\mathrm{H}$, Noeh CC, Kato Y, Takeuchi T, Noguchi T, Kadowaki $H$, Sedlak TW, Ishizuka K, Ichijo H, Sawa A. Role of apoptosis signal-regulating kinase 1 (ASK1) as an activator of the GAPDH-Siah1 stress-signaling cascade. J Biol Chem. 2015; 290:56-64.

https://doi.org/10.1074/jbc.M114.596205 PMID:25391652

26. Muronetz VI, Medvedeva MV, Sevostyanova IA, Schmalhausen EV. Modification of Glyceraldehyde-3Phosphate Dehydrogenase with Nitric Oxide: Role in Signal Transduction and Development of Apoptosis. Biomolecules. 2021; 11:1656.

https://doi.org/10.3390/biom11111656

PMID: 34827652

27. Tian X, Gong L, Jin A, Wang Y, Zhou X, Tan Y. E3 ubiquitin ligase siah1 nuclear accumulation is critical for homocysteineinduced impairment of C6 astroglioma cells. Mol Med Rep. 2019; 20:2227-35. https://doi.org/10.3892/mmr.2019.10449 PMID:31322210

28. Butera G, Mullappilly N, Masetto F, Palmieri M, Scupoli MT, Pacchiana R, Donadelli M. Regulation of Autophagy by Nuclear GAPDH and Its Aggregates in Cancer and Neurodegenerative Disorders. Int J Mol Sci. 2019; 20:2062. https://doi.org/10.3390/ijms20092062 PMID:31027346

29. Hardie DG, Schaffer BE, Brunet A. AMPK: An EnergySensing Pathway with Multiple Inputs and Outputs. Trends Cell Biol. 2016; 26:190-201. 
https://doi.org/10.1016/j.tcb.2015.10.013 PMID:26616193

30. Garcia D, Shaw RJ. AMPK: Mechanisms of Cellular Energy Sensing and Restoration of Metabolic Balance. Mol Cell. 2017; 66:789-800.

https://doi.org/10.1016/i.molcel.2017.05.032 PMID:28622524

31. Lin SC, Hardie DG. AMPK: Sensing Glucose as well as Cellular Energy Status. Cell Metab. 2018; 27: 299313.

https://doi.org/10.1016/i.cmet.2017.10.009 PMID:29153408

32. Herzig S, Shaw RJ. AMPK: guardian of metabolism and mitochondrial homeostasis. Nat Rev Mol Cell Biol. 2018; 19:121-35.

https://doi.org/10.1038/nrm.2017.95

PMID:28974774

33. Carling D. AMPK signalling in health and disease. Curr Opin Cell Biol. 2017; 45:31-7.

https://doi.org/10.1016/j.ceb.2017.01.005

PMID: $\underline{28232179}$

34. Salminen A, Kaarniranta K, Kauppinen A. Age-related changes in AMPK activation: Role for AMPK phosphatases and inhibitory phosphorylation by upstream signaling pathways. Ageing Res Rev. 2016; 28:15-26.

https://doi.org/10.1016/i.arr.2016.04.003

PMID:27060201

35. Mihaylova MM, Shaw RJ. The AMPK signalling pathway coordinates cell growth, autophagy and metabolism. Nat Cell Biol. 2011; 13:1016-23.

https://doi.org/10.1038/ncb2329

PMID:21892142

36. Li Y, Chen Y. AMPK and Autophagy. Adv Exp Med Biol. 2019; 1206:85-108. https://doi.org/10.1007/978-981-15-0602-4 4 PMID:31776981

37. Toyama EQ, Herzig S, Courchet J, Lewis TL, Jr Losón OC, Hellberg K, Young NP, Chen H, Polleux F, Chan DC, Shaw RJ. Metabolism. AMP-activated protein kinase mediates mitochondrial fission in response to energy stress. Science. 2016; 351:275-81.

https://doi.org/10.1126/science.aab4138 PMID:26816379

38. Yeo EJ. Hypoxia and aging. Exp Mol Med. 2019; 51:1-15.

https://doi.org/10.1038/s12276-019-0233-3

PMID:31221957

39. Rabinovitch RC, Samborska B, Faubert B, Ma EH, Gravel SP, Andrzejewski S, Raissi TC, Pause A, St-Pierre J, Jones RG. AMPK Maintains Cellular Metabolic Homeostasis through Regulation of Mitochondrial Reactive Oxygen Species. Cell Rep. 2017; 21:1-9.

https://doi.org/10.1016/j.celrep.2017.09.026

PMID:28978464

40. Burkewitz K, Zhang Y, Mair WB. AMPK at the nexus of energetics and aging. Cell Metab. 2014; 20:10-25.

https://doi.org/10.1016/j.cmet.2014.03.002 PMID:24726383

41. Liu F, Benashski SE, Persky R, Xu Y, Li J, McCullough LD. Age-related changes in AMP-activated protein kinase after stroke. Age (Dordr). 2012; 34:157-68. https://doi.org/10.1007/s11357-011-9214-8 PMID:21360073

42. Jang HJ, Yang KE, Oh WK, Lee SI, Hwang IH, Ban KT, Yoo HS, Choi JS, Yeo EJ, Jang IS. Nectandrin Bmediated activation of the AMPK pathway prevents cellular senescence in human diploid fibroblasts by reducing intracellular ROS levels. Aging (Albany NY). 2019; 11:3731-49.

https://doi.org/10.18632/aging.102013 PMID:31199782

43. Salminen A, Kauppinen A, Kaarniranta K. AMPK activation inhibits the functions of myeloid-derived suppressor cells (MDSC): impact on cancer and aging. J Mol Med (Berl). 2019; 97:1049-64. https://doi.org/10.1007/s00109-019-01795-9 PMID:31129755

44. Jiang S, Li T, Yang Z, Yi W, Di S, Sun Y, Wang D, Yang Y. AMPK orchestrates an elaborate cascade protecting tissue from fibrosis and aging. Ageing Res Rev. 2017; 38:18-27.

https://doi.org/10.1016/i.arr.2017.07.001 PMID:28709692

45. Stancu AL. AMPK activation can delay aging. Discoveries (Craiova). 2015; 3:e53.

https://doi.org/10.15190/d.2015.45 PMID:32309575

46. Reznick RM, Zong H, Li J, Morino K, Moore IK, Yu HJ, Liu ZX, Dong J, Mustard KJ, Hawley SA, Befroy D, Pypaert $M$, Hardie DG, et al. Aging-associated reductions in AMP-activated protein kinase activity and mitochondrial biogenesis. Cell Metab. 2007; 5:151-6. https://doi.org/10.1016/i.cmet.2007.01.008 PMID: 17276357

47. Qi D, Young LH. AMPK: energy sensor and survival mechanism in the ischemic heart. Trends Endocrinol Metab. 2015; 26:422-9. https://doi.org/10.1016/j.tem.2015.05.010 PMID:26160707

48. Qin S, Tang $\mathrm{H}$, Li W, Gong $\mathrm{Y}$, Li S, Huang J, Fang $\mathrm{Y}$, Yuan W, Liu Y, Wang S, Guo Y, Guo Y, Xu Z. AMPK and 
its Activator Berberine in the Treatment of Neurodegenerative Diseases. Curr Pharm Des. 2020; 26:5054-66.

https://doi.org/10.2174/1381612826666200523172334 PMID:32445451

49. Wang X, Zimmermann HR, Ma T. Therapeutic Potential of AMP-Activated Protein Kinase in Alzheimer's Disease. J Alzheimers Dis. 2019; 68:33-8. https://doi.org/10.3233/JAD-181043 PMID:30776001

50. Kwon HJ, Rhim JH, Jang IS, Kim GE, Park SC, Yeo EJ. Activation of AMP-activated protein kinase stimulates the nuclear localization of glyceraldehyde 3phosphate dehydrogenase in human diploid fibroblasts. Exp Mol Med. 2010; 42:254-69. https://doi.org/10.3858/emm.2010.42.4.025 PMID:20177150

51. Childs BG, Durik M, Baker DJ, van Deursen JM. Cellular senescence in aging and age-related disease: from mechanisms to therapy. Nat Med. 2015; 21:1424-35.

https://doi.org/10.1038/nm.4000 PMID:26646499

52. Yeo EJ, Jang IS, Lim HK, Ha KS, Park SC. Agonistspecific differential changes of cellular signal transduction pathways in senescent human diploid fibroblasts. Exp Gerontol. 2002; 37:871-83. https://doi.org/10.1016/s0531-5565(02)00027-x PMID:12086695

53. Yeo EJ, Park SC. Age-dependent agonist-specific dysregulation of membrane-mediated signal transduction: emergence of the gate theory of aging. Mech Ageing Dev. 2002; 123:1563-78. https://doi.org/10.1016/s0047-6374(02)00092-1 PMID:12470894

54. Li Q, Bai L, Liu N, Wang M, Liu JP, Liu P, Cong YS. Increased polymerase I and transcript release factor (Cavin-1) expression attenuates platelet-derived growth factor receptor signalling in senescent human fibroblasts. Clin Exp Pharmacol Physiol. 2014; 41:169-73.

https://doi.org/10.1111/1440-1681.12202 PMID:24471649

55. Rhim JH, Jang IS, Song KY, Ha MK, Cho SC, Yeo EJ, Park SC. Lysophosphatidic acid and adenylyl cyclase inhibitor increase proliferation of senescent human diploid fibroblasts by inhibiting adenosine monophosphateactivated protein kinase. Rejuvenation Res. 2008; 11:781-92.

https://doi.org/10.1089/rej.2008.0709

PMID:18729810

56. Bonnans C, Chou J, Werb Z. Remodelling the extracellular matrix in development and disease. Nat Rev Mol Cell Biol. 2014; 15:786-801. https://doi.org/10.1038/nrm3904 PMID:25415508

57. Wu X, Cai J, Zuo Z, Li J. Collagen facilitates the colorectal cancer stemness and metastasis through an integrin/PI3K/AKT/Snail signaling pathway. Biomed Pharmacother. 2019; 114:108708. https://doi.org/10.1016/i.biopha.2019.108708 PMID: $\underline{30913493}$

58. Qin W, Cao L, Massey IY. Role of PI3K/Akt signaling pathway in cardiac fibrosis. Mol Cell Biochem. 2021; 476:4045-59.

https://doi.org/10.1007/s11010-021-04219-w PMID:34244974

59. Jiang N, Dai Q, Su X, Fu J, Feng X, Peng J. Role of PI3K/AKT pathway in cancer: the framework of malignant behavior. Mol Biol Rep. 2020; 47:4587629.

https://doi.org/10.1007/s11033-020-05435-1 PMID: $\underline{32333246}$

60. Wu C, Qiu S, Zhu X, Lin H, Li L. OCT1-Mediated Metformin Uptake Regulates Pancreatic Stellate Cell Activity. Cell Physiol Biochem. 2018; 47:1711-20. https://doi.org/10.1159/000491003 PMID:29949790

61. Cieslik KA, Trial J, Entman ML. Aicar treatment reduces interstitial fibrosis in aging mice: Suppression of the inflammatory fibroblast. J Mol Cell Cardiol. 2017; 111:81-5.

https://doi.org/10.1016/j.yjmcc.2017.08.003 PMID:28826664

62. Chen DQ, Wang YN, Vaziri ND, Chen L, Hu HH, Zhao YY. Poricoic acid A activates AMPK to attenuate fibroblast activation and abnormal extracellular matrix remodelling in renal fibrosis. Phytomedicine. 2020; 72:153232.

https://doi.org/10.1016/i.phymed.2020.153232 PMID:32460034

63. Tsogbadrakh B, Ju KD, Lee J, Han M, Koh J, Yu Y, Lee H, Yu KS, Oh YK, Kim HJ, Ahn C, Oh KH. HL156A, a novel pharmacological agent with potent adenosinemonophosphate-activated protein kinase (AMPK) activator activity ameliorates renal fibrosis in a rat unilateral ureteral obstruction model. PLoS One. 2018; 13:e0201692.

https://doi.org/10.1371/journal.pone.0201692 PMID:30161162

64. Rangarajan S, Bone NB, Zmijewska AA, Jiang S, Park DW, Bernard K, Locy ML, Ravi S, Deshane J, Mannon RB, Edward Abraham E, Darley-Usmar V, Thannickal VJ, Zmijewski JW. Metformin reverses established lung fibrosis in a bleomycin model. Nat Med. 2018; 24:1121-7. 
https://doi.org/10.1038/s41591-018-0087-6 PMID:29967351

65. Li SX, Li C, Pang XR, Zhang J, Yu GC, Yeo AJ, Lavin MF, Shao H, Jia Q, Peng C. Metformin Attenuates SilicaInduced Pulmonary Fibrosis by Activating Autophagy via the AMPK-mTOR Signaling Pathway. Front Pharmacol. 2021; 12:719589.

https://doi.org/10.3389/fphar.2021.719589 PMID:34434111

66. Wang W, Yang X, López de Silanes I, Carling D, Gorospe $M$. Increased AMP:ATP ratio and AMPactivated protein kinase activity during cellular senescence linked to reduced HuR function. J Biol Chem. 2003; 278:27016-23.

https://doi.org/10.1074/jbc.M300318200 PMID: 12730239

67. Jin $Q$, Jhun BS, Lee $S H$, Lee J, Pi Y, Cho YH, Baik HH, Kang I. Differential regulation of phosphatidylinositol 3-kinase/Akt, mitogen-activated protein kinase, and AMP-activated protein kinase pathways during menadione-induced oxidative stress in the kidney of young and old rats. Biochem Biophys Res Commun. 2004; 315:555-61. https://doi.org/10.1016/j.bbrc.2004.01.093 PMID:14975736

68. Mulligan JD, Gonzalez AA, Kumar R, Davis AJ, Saupe $\mathrm{KW}$. Aging elevates basal adenosine monophosphateactivated protein kinase (AMPK) activity and eliminates hypoxic activation of AMPK in mouse liver. J Gerontol A Biol Sci Med Sci. 2005; 60:21-7. https://doi.org/10.1093/gerona/60.1.21 PMID: 15741278

69. Hardman SE, Hall DE, Cabrera AJ, Hancock CR, Thomson DM. The effects of age and muscle contraction on AMPK activity and heterotrimer composition. Exp Gerontol. 2014; 55:120-8. https://doi.org/10.1016/i.exger.2014.04.007 PMID:24747582

70. Salminen A, Kaarniranta K. AMP-activated protein kinase (AMPK) controls the aging process via an integrated signaling network. Ageing Res Rev. 2012; 11:230-41.

https://doi.org/10.1016/j.arr.2011.12.005 PMID:22186033

71. Bain J, Plater L, Elliott M, Shpiro N, Hastie CJ, McLauchlan H, Klevernic I, Arthur JS, Alessi DR, Cohen $P$. The selectivity of protein kinase inhibitors: a further update. Biochem J. 2007; 408:297-315. https://doi.org/10.1042/BJ20070797 PMID: 17850214

72. Kwon HJ, Kim GE, Lee YT, Jeong MS, Kang I, Yang D, Yeo EJ. Inhibition of platelet-derived growth factor receptor tyrosine kinase and downstream signaling pathways by Compound C. Cell Signal. 2013; 25:883-97. https://doi.org/10.1016/j.cellsig.2012.12.016 PMID:23277201

73. Huang SW, Wu CY, Wang YT, Kao JK, Lin CC, Chang CC, Mu SW, Chen YY, Chiu HW, Chang $\mathrm{CH}$, Liang SM, Chen YJ, Huang JL, Shieh JJ. p53 modulates the AMPK inhibitor compound $\mathrm{C}$ induced apoptosis in human skin cancer cells. Toxicol Appl Pharmacol. 2013; 267:113-24.

https://doi.org/10.1016/i.taap.2012.12.016 PMID:23274516

74. Lee YT, Lim SH, Lee B, Kang I, Yeo EJ. Compound C Inhibits B16-F1 Tumor Growth in a Syngeneic Mouse Model Via the Blockage of Cell Cycle Progression and Angiogenesis. Cancers (Basel). 2019; 11:823. https://doi.org/10.3390/cancers11060823 PMID: $\underline{31200558}$

75. Peairs A, Radjavi A, Davis S, Li L, Ahmed A, Giri S, Reilly CM. Activation of AMPK inhibits inflammation in MRL/Ipr mouse mesangial cells. Clin Exp Immunol. 2009; 156:542-51.

https://doi.org/10.1111/i.1365-2249.2009.03924.x PMID: 19438609

76. Jhun BS, Jin Q, Oh YT, Kim SS, Kong Y, Cho YH, Ha J, Baik $\mathrm{HH}$, Kang I. 5-Aminoimidazole-4-carboxamide riboside suppresses lipopolysaccharide-induced TNFalpha production through inhibition of phosphatidylinositol 3-kinase/Akt activation in RAW 264.7 murine macrophages. Biochem Biophys Res Commun. 2004; 318:372-80.

https://doi.org/10.1016/j.bbrc.2004.04.035 PMID:15120611

77. Kovacic S, Soltys CL, Barr AJ, Shiojima I, Walsh K, Dyck JR. Akt activity negatively regulates phosphorylation of AMP-activated protein kinase in the heart. J Biol Chem. 2003; 278:39422-7.

https://doi.org/10.1074/jbc.M305371200 PMID:12890675

78. King TD, Song L, Jope RS. AMP-activated protein kinase (AMPK) activating agents cause dephosphorylation of Akt and glycogen synthase kinase-3. Biochem Pharmacol. 2006; 71:1637-47. https://doi.org/10.1016/j.bcp.2006.03.005 PMID: 16620785

79. Rattan R, Giri S, Singh AK, Singh I. 5-Aminoimidazole-4carboxamide-1-beta-D-ribofuranoside inhibits cancer cell proliferation in vitro and in vivo via AMP-activated protein kinase. J Biol Chem. 2005; 280:39582-93.

https://doi.org/10.1074/ibc.m507443200 PMID: 16176927

80. Cao C, Lu S, Kivlin R, Wallin B, Card E, Bagdasarian A, Tamakloe T, Chu WM, Guan KL, Wan Y. AMP- 
activated protein kinase contributes to UV- and $\mathrm{H} 2 \mathrm{O} 2$-induced apoptosis in human skin keratinocytes. J Biol Chem. 2008; 283:28897-908.

https://doi.org/10.1074/jbc.m804144200

PMID:18715874 Retraction in: J Biol Chem. 2010; 285:14842.

https://doi.org/10.1074/ibc.A109.804144

PMID:29874310

81. Càmpas $C$, Lopez JM, Santidriàn AF, Barragàn $M$, Bellosillo B, Colomer D, Gil J. Acadesine activates AMPK and induces apoptosis in B-cell chronic lymphocytic leukemia cells but not in T lymphocytes. Blood. 2003; 101:3674-80.

https://doi.org/10.1182/blood-2002-07-2339 PMID:12522004

82. Theodoropoulou S, Kolovou PE, Morizane $\mathrm{Y}$, Kayama M, Nicolaou F, Miller JW, Gragoudas E, Ksander BR, Vavvas DG. Retinoblastoma cells are inhibited by aminoimidazole carboxamide ribonucleotide (AICAR) partially through activation of AMP-dependent kinase. FASEB J. 2010; 24:2620-30.

https://doi.org/10.1096/fj.09-152546 PMID:20371623

83. Tulipano G, Faggi L, Cacciamali A, Spinello M, Cocchi $D$, Giustina A. Role of AMP-activated protein kinase activators in antiproliferative multi-drug pituitary tumour therapies: effects of combined treatments with compounds affecting the mTOR-p70S6 kinase axis in cultured pituitary tumour cells. J Neuroendocrinol. 2015; 27:20-32.

https://doi.org/10.1111/jne.12231

PMID:25323047

84. Lee YK, Park SY, Kim YM, Lee WS, Park OJ. AMP kinase/cyclooxygenase-2 pathway regulates proliferation and apoptosis of cancer cells treated with quercetin. Exp Mol Med. 2009; 41:201-7. https://doi.org/10.3858/emm.2009.41.3.023 PMID:19293639

85. Nagata D, Kiyosue A, Takahashi M, Satonaka $H$, Tanaka K, Sata M, Nagano T, Nagai R, Hirata Y. A new constitutively active mutant of AMP-activated protein kinase inhibits anoxia-induced apoptosis of vascular endothelial cell. Hypertens Res. 2009; 32:133-9. https://doi.org/10.1038/hr.2008.25 PMID:19262472
86. Han X, Wang B, Sun Y, Huang J, Wang X, Ma W, Zhu Y, $\mathrm{Xu}$ R, Jin H, Liu N. Metformin Modulates High Glucose-Incubated Human Umbilical Vein Endothelial Cells Proliferation and Apoptosis Through AMPK/ CREB/BDNF Pathway. Front Pharmacol. 2018; 9:1266. https://doi.org/10.3389/fphar.2018.01266 PMID: 30459620

87. Dastoor Z, Dreyer JL. Potential role of nuclear translocation of glyceraldehyde-3-phosphate dehydrogenase in apoptosis and oxidative stress. J Cell Sci. 2001; 114:1643-53.

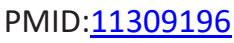

88. Hara MR, Snyder SH. Nitric oxide-GAPDH-Siah: a novel cell death cascade. Cell Mol Neurobiol. 2006; 26:527-38.

https://doi.org/10.1007/s10571-006-9011-6 PMID:16633896

89. Huang Q, Lan F, Zheng Z, Xie F, Han J, Dong L, Xie Y, Zheng F. Akt2 kinase suppresses glyceraldehyde-3phosphate dehydrogenase (GAPDH)-mediated apoptosis in ovarian cancer cells via phosphorylating GAPDH at threonine 237 and decreasing its nuclear translocation. J Biol Chem. 2011; 286:42211-20. https://doi.org/10.1074/jbc.M111.296905 PMID:21979951

90. Zhai D, Chin K, Wang M, Liu F. Disruption of the nuclear p53-GAPDH complex protects against ischemia-induced neuronal damage. Mol Brain. 2014; $7: 20$.

https://doi.org/10.1186/1756-6606-7-20 PMID:24670206

91. Yeo EJ, Hwang YC, Kang CM, Choy HE, Park SC. Reduction of UV-induced cell death in the human senescent fibroblasts. Mol Cells. 2000; 10:415-22. PMID:10987139

92. Rhim JH, Jang IS, Kwon ST, Song KY, Yeo EJ, Park SC. Activation of wound healing in aged rats by altering the cellular mitogenic potential. J Gerontol A Biol Sci Med Sci. 2010; 65:704-11. https://doi.org/10.1093/gerona/glq065 PMID:20457578 


\section{SUPPLEMENTARY MATERIALS}

\section{Supplementary Figures}
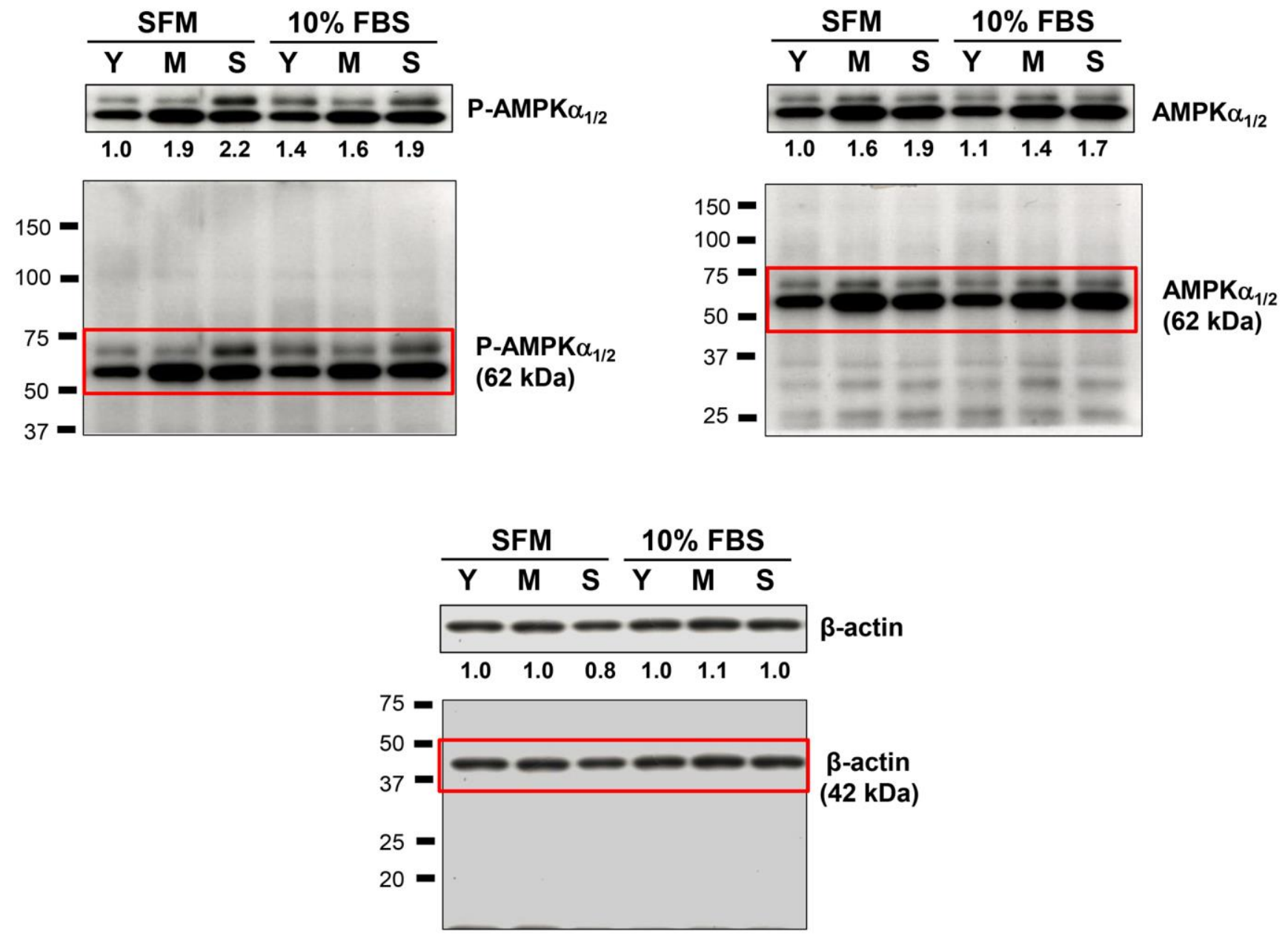

Supplementary Figure 1. A representative whole blot for western blot analysis of each protein in Figure 4A. Subconfluent young (Y, PD 12), middle (M, PD 48), and senescent (S, PD 86) HDFs were incubated with SFM or $10 \%$ FBS medium for 2 days. Cells were lysed in a lysis buffer, and $45 \mu \mathrm{g}$ of protein from each lysate was assessed for the levels of phosphorylated AMPK $\alpha_{1 / 2}$ on Thr ${ }^{172}$ $\left(\mathrm{P}-\mathrm{AMPK} \alpha_{1 / 2}\right)$, total $\mathrm{AMPK} \alpha_{1 / 2}$, and $\beta$-actin by western blot analysis. The band densities were normalized against $\beta$-actin and the fold changes compared to that of young cells (Y/SFM) are written under each band. A representative whole blot for western blot analysis of each protein are shown below each band. 

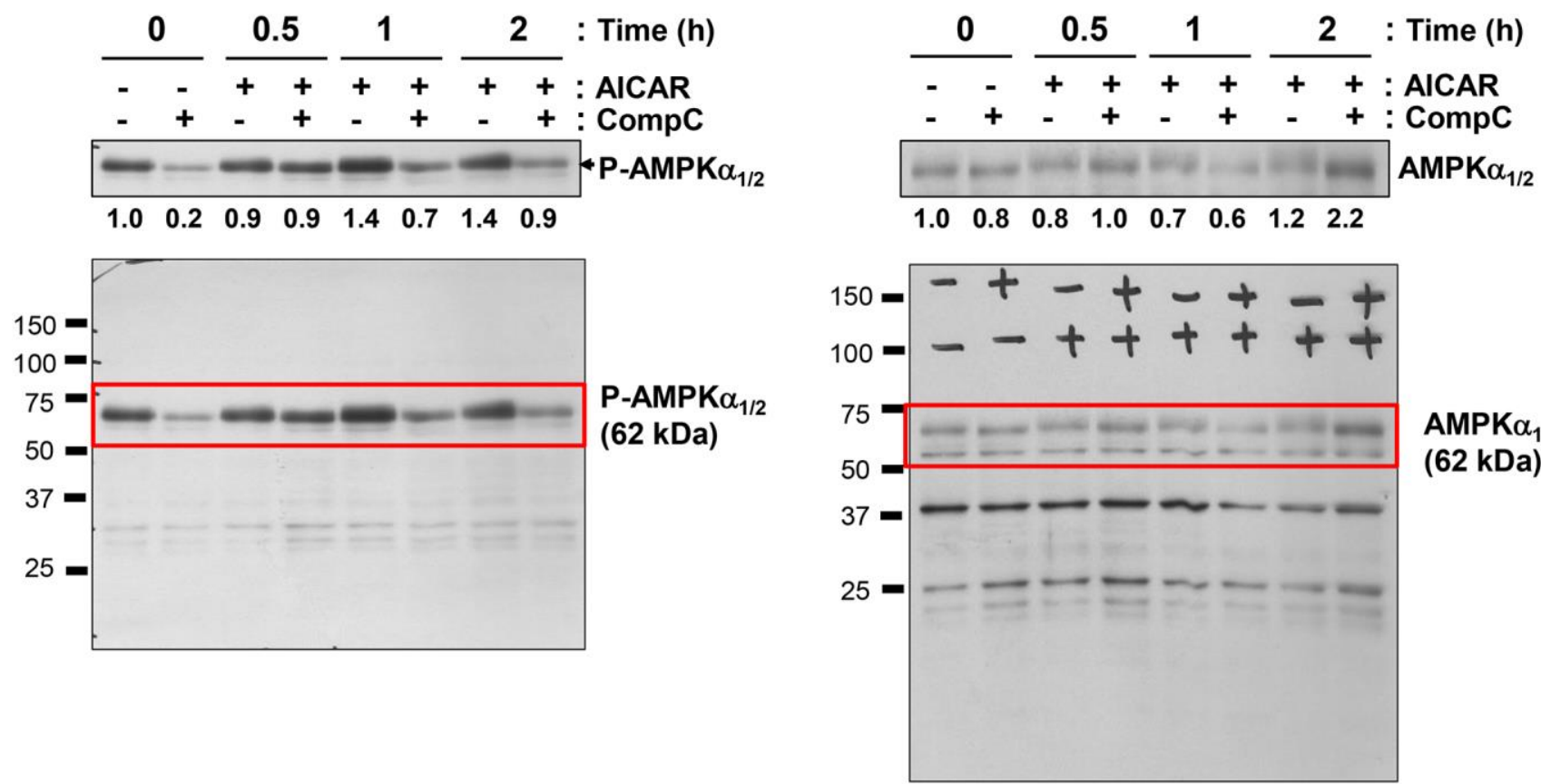

AMPK $\alpha_{1 / 2}$ $(62 \mathrm{kDa})$
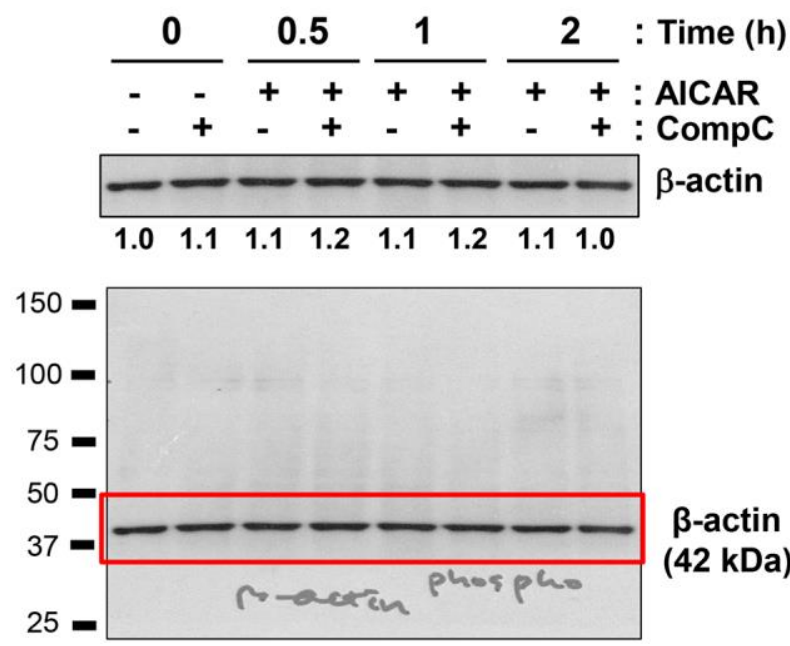

\section{$\beta$-actin (42 kDa)}

Supplementary Figure 2. A representative whole blot for western blot analysis of each protein in Figure 4B. Subconfluent young (PD 20) and senescent (PD 74) HDFs were treated with vehicle (-) or 1 mM AICAR and/or $10 \mu M$ CompC (+) for 2 days. Cells in A and $B$ were lysed in a lysis buffer, and $45 \mu \mathrm{g}$ of protein from each lysate was assessed for the levels of phosphorylated $A M P K \alpha_{1 / 2}$ on $T^{172}$ $\left(\mathrm{P}-\mathrm{AMPK} \alpha_{1 / 2}\right)$, total $\mathrm{AMPK} \alpha_{1 / 2}$, and $\beta$-actin by western blot analysis. The band densities were normalized against $\beta$-actin and the fold changes compared to that of vehicle treated control cells (-/-) are written under each band. A representative whole blot for western blot analysis of each protein are shown below each band. 

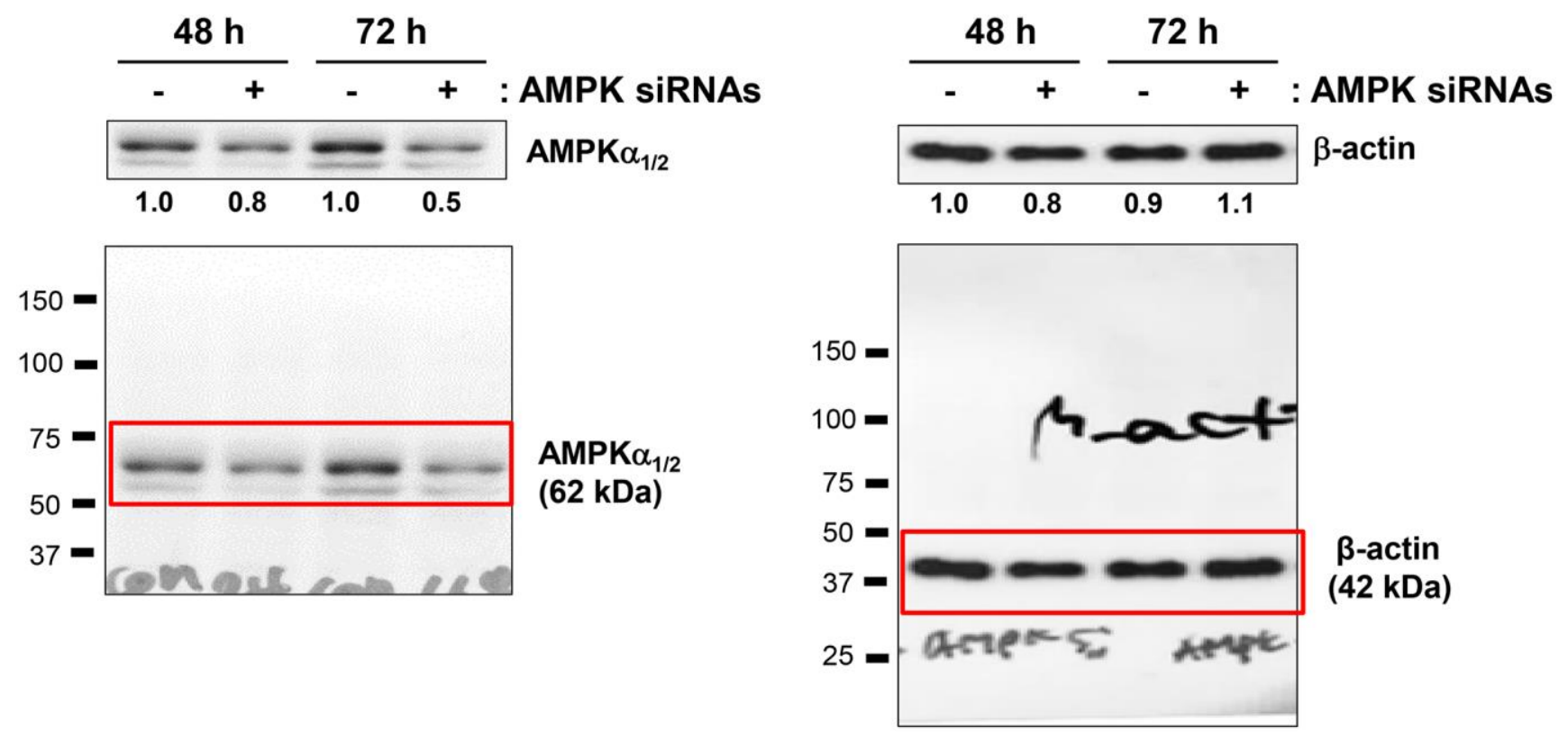

Supplementary Figure 3. A representative whole blot for western blot analysis of each protein in Figure 5A. Senescent HDFs were transfected with control scrambled siRNA duplexes (-) or siRNAs against AMPK $\alpha_{1 / 2}(+)$ for 48 and $72 \mathrm{~h}$ in DMEM with $10 \%$ FBS. Cells were harvested at the indicated times after transfection, and lysates containing the same amount of protein ( $45 \mu \mathrm{g})$ were assessed by western blot analysis using polyclonal anti-AMPK $\alpha_{1 / 2}$ and anti- $\beta$-actin antibodies. The band densities were normalized against $\beta$-actin and the fold changes of $A M P K \alpha_{1 / 2}$ in AMPK siRNA-transfected cells (+) compared to that of scrambled siRNA-treated control cells (-) are written under each band. A representative whole blot for western blot analysis of each protein are shown below each band. 